\title{
Spherical Robots for Special Purposes: A Review on Current Possibilities
}

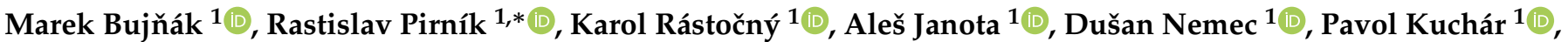 \\ Tomáš Tichý $^{2}$ iD and Zbigniew Lukasik $^{3}$ iD
}

1 Faculty of Electrical Engineering and Information Technology, University of Zilina, 01026 Zilina, Slovakia; marek.bujnak@feit.uniza.sk (M.B.); karol.rastocny@feit.uniza.sk (K.R.); ales.janota@feit.uniza.sk (A.J.); dusan.nemec@feit.uniza.sk (D.N.); pavol.kuchar@feit.uniza.sk (P.K.)

2 Faculty of Transportation Sciences, Czech Technical University in Prague, 11000 Prague, Czech Republic; tomas.Tichy@cvut.cz

3 Faculty of Transport, Electrical Engineering and Informatics, University of Technology and Humanities in Radom, 26-600 Radom, Poland; z.lukasik@uthrad.pl

* Correspondence: rastislav.pirnik@feit.uniza.sk

Citation: Bujňák, M.; Pirník, R.; Rástočný, K.; Janota, A.; Nemec, D.; Kuchár, P.; Tichý, T.; Łukasik, Z. Spherical Robots for Special Purposes: A Review on Current Possibilities. Sensors 2022, 22, 1413. https://doi.org/10.3390/s22041413 Academic Editors: Igor Korobiichuk, Michał Nowicki and Cosimo Distante

Received: 8 December 2021 Accepted: 10 February 2022 Published: 12 February 2022

Publisher's Note: MDPI stays neutral with regard to jurisdictional claims in published maps and institutional affiliations.

Copyright: (C) 2022 by the authors. Licensee MDPI, Basel, Switzerland. This article is an open access article distributed under the terms and conditions of the Creative Commons Attribution (CC BY) license (https:// creativecommons.org/licenses/by/ $4.0 /)$.

\begin{abstract}
The review discusses the possibilities of different driving mechanisms and sensors of spherical robots, and a special kind of mobile robots is introduced and discussed. The sensors discussed can expand robots' sensing capabilities which are typically very limited. Most spherical robots have holonomic characteristics and protect the inner environment using a shell. Today, there are a diversity of driving mechanisms. Therefore, this article provides a review of all of them and identifies their basic properties. Accordingly, many spherical robots have only inner sensors for moving, balancing, driving, etc. However, a few of them are also equipped with sensors that can measure environmental properties. Therefore, in this paper, we propose the possibility of using such sensors as cameras, LiDARs, thermocouples, and gas sensors, which can be used for special purposes underground, for example, in mines, underground tunnels, or road tunnels. After combining all components are combined, it is possible to design a special type of spherical robot designed for underground exploration, such as accidents in mines or road tunnels.
\end{abstract}

Keywords: spherical robot; mobile robot; inertial sensors; cameras; temperature sensors; gas sensors; LiDAR; special applications; tunnel applications

\section{Introduction}

The "special purpose", in this case, means accidents in the underground space, more specifically, in the road tunnel. During a tunnel accident, various situations can occur, such as leakage of dangerous liquids and gases into the environment, fire, the danger of injury or death of the participants in the traffic accident, huge material damage, and more. Therefore, the fastest and most accurate intervention of the rescue services is needed. However, rescue services are not always able to intervene directly. They would be exposed to risk because they do not know the environment. They need to sufficiently gain knowledge of all the details of the accident.

Based on Reference [1], the authors tried to set the passive sensor in motion on the basis of a certain type of driving mechanism. The first part showed the possibilities of spherical robots to be used in different field of applications (Section 1.1). The survey showed that the considered sensors from the Reference [1] must be placed inside the shell of the spherical robot so that nothing prevents it from smoothing motion. Subsequently, an overview of possible solutions for the control mechanism of the spherical robot (Section 2) was created. This driving mechanism must meet conditions, such as stop on a sloping surface (rising and falling in of a tunnel) and overcoming a step obstacle (sidewalk in tunnels), and, at the same time, it was possible to place sensors on the driving mechanism. In Section 3, an overview 
was created of inertial sensors, which can be used for a spherical robot for navigation in underground space. Given the sensors that were used in Reference [1], we tried to expand and create an overview of cheap but reliable sensors (Section 4). We focused mainly on measuring gases that are dangerous in accidents in underground and closed spaces (CO and $\mathrm{CO}_{2}$ ). In addition, the temperature around the spherical robot is necessary to measure because, in an underground space, the temperature can increase immediately. It is also appropriate to use cameras (visible spectrum and IR spectrum) for reconnaissance purposes, so that rescuers do not enter an unsafe environment and, thus, be exposed to some risk. In case the underground space is smoky, or otherwise has reduced visibility, it is appropriate that the spherical robot has LiDAR. This sensor can be used to collect data and then create a 2D map of the space. All these sensors will provide rescue services with a wider range of information that can lead to improved and more effective intervention. The article also includes a section (Section 5) where the authors focused on special applications of mobile robots in the field of surveillance, reconnaissance, fire, search, and rescue. Although this article falls into the category of review, the authors have decided to publish the direction of future research. It connects the sensory part with the driving mechanism and, thus, creates a new perspective on the issue of rescue and reconnaissance robots germane to in-ground space (Section 6), such as the tunnels. By combining these parts, some properties of the spherical robot will be improved. One of the authors, in his PhD work, deals with this issue.

\subsection{Applications of Spherical Robots}

A spherical robot (SR) is a special kind of mobile robot that has a ball's characteristic and is made up of the steering and the driving mechanism being placed inside of the spherical shell. Most SRs depend on internal weight distribution or the relocation of the center of the mass point. The SR has the character of flexible movement and the spherical shell cover that protects the inner mechanism. In line with this, the SR can be utilized in an environment with dangerous properties, such as in rain or a flammable area.

The development of SRs has recently received significant attention. This type of robot has several advantages, as a of robot of this kind, in comparison with the traditional robots with wheels, belts, or legs [2]:

- the outer shell protects the whole system of the robots,

- the smoothness of movement,

- great power effectivity,

- the motion can be omnidirectional due to the design,

- the possibility of movement on water or throwing a robot, and

- the robot cannot be overturned.

Besides the advantages, SRs also have several disadvantages, such as:

- the small maximum torque,

- problems with movement on uneven and steep terrain,

- limitations in the use of environmental sensors,

- the size of the shell depends on the construction of the inner driving mechanism, and

- complicated design.

The SR can be applied to various fields of application. The first example to be considered is DAEDALUS [3], which will be used to explore the moon caves, or group of rovers equipped with minimal control mechanisms based on design of Tumbleweed dedicated to explore Mars [4]. Similar to drones, SR can also join swarms and move as one whole. An example of such a robot is FreeBOT [5], which is able to join and move as a swarm. Accordingly, these robots can physically join and move as one robot and also can overcome obstacles together. Alternatively, a swarm of SRs might create a sensor network designed to measure ambient temperature and relative humidity [6]. One of the new things is a hybrid SR, having been coupled connected with a drone. Reference [7] puts forward a robot being able to climb, roll, and fly, by combining four-legged crawling, wheel-rolling, and four- 
rotor-flying movement methods. Similarly, Reference [8] focuses on a robot being capable of rolling on both water surfaces and on ground surfaces and flying in the air by changing the pitch angle of each propeller and adopting corresponding control algorithms. In Reference [9], authors propose a micro spherical rolling and flying robot. In addition, a novel spherical robot, named flying-crawling spherical robot, is designed in Reference [10]. It can fly or roll on the ground with its single rotor and eight tail fins. Some analogical examples of hybrid SRs are swimming or underwater SR. Specifically, Reference [11] provides a description of a new concept of spherical underwater robot propelled by thrust vector synthetic jet actuator. Furthermore, a novel amphibious spherical robot system with Jacobian matrix kinematics verification is proposed in Reference [12]. Authors in Reference [13] came up with a legged, Multi-Vectored Water-Jet Composite Propulsion Mechanism (LMVWCPM) designed with four legs, one of which contains three connecting rod parts, one water-jet thruster, and three joints driven by digital servos. Lastly, Reference [14] introduces system able to track the color coded pattern simultaneously sending feedback on the orientation command to the on board controller to achieve tracking and following of a given target underwater. References $[15,16]$ deal with SRs which were interconnected and used as wheels for an omnidirectional chassis. SRs can be used also for exploration, as well as for protection, of large areas or rooms [17]. In Reference [18], the hardware division of a technological solution for child monitoring outlined development of a semi-autonomous spherical robot to follow a subject's movements and moves throughout the room. Reference [19] presents a spherical robot carrying a binocular stereo vision, referred to as VisionBot. The robot aims to use stereo vision to enhance the environmental perception of spherical robots, thus reducing cumulative errors caused by sliding, mechanical clearance, and model error. Authors in Reference [20] give description of a computer vision system consisting of several spherical mobile devices with a digital camera and microcomputer inside. Another field where SRs can be used is children's toys [21].

The motion of SRs must be described in terms of the kinematics and dynamics of their behavior. Hence, the following references comprise detailed descriptions of some of them. Reference [22] presents a large-size spherical robot used for polar scientific research, which can drive by utilizing the wind. In case the wind is strong, the wind drives the robot, and the inside instrument is intended for adjustment of the direction. On the contrary, if the wind speed low, it can move and steer by inertia drive though the pendulum. Authors in Reference [23] are exploring the derivation of the Lagrangian for different configurations of spherical robots, taking Euler Lagrange equations and additional constraints for the generalized velocities into consideration. The degrees of freedom are specified with rotation matrices and linear displacement vectors, thus allowing to firstly determine the necessary elements for all the models in a procedural way and, secondly, to obtain the dynamics of the system. One of the models obtained in the way mentioned above is used for simple velocity control tests with two approaches, using the torque and velocity of the rotatory actuators as control inputs. As pointed out in Reference [24], an internal device's climbing up the internal surface of the shell results in a gravity-powered pendulum effect, propelling the robot forward up to a speed of $0.16 \mathrm{~m} / \mathrm{s}$. Reference [25] is considering the motion of a spherical robot with periodically changing moments of inertia and gyrostatic momentum. Equations of motion are derived within the framework of the model of "rubber" rolling (without slipping and twisting). Authors in Reference [26] derive a dynamic model of a spherical rolling robot having new driving mechanism equipped with a gyro and design a controller to stabilize a desired translational motion of the robot. Due to the angular momentum of the gyro, nutation motion of the internal mechanism of the robot might be caused. 


\section{Driving Mechanism}

Generally, driving mechanisms can be divided into three main types, in terms of the used driving method:

- direct driving method,

- gravity driving method, and

- angular momentum driving method.

In general, correct design of the drive mechanism, as well as design of the controller, plays a pivotal role for correct control of the outer shell of SRs. Despite the fact that authors of References [2,27] have offered the overview of driving mechanisms of SRs, both publications only cited articles and research published up until 2012. For this reason, the following part of the article deals with an updated overview of all the driving mechanisms that have been preferably indexed in the WoS, Scopus, and IEEE databases, up to 2021.

\subsection{Kinematics of a Spherical Robot}

In general, the spherical robot has 3 degrees of freedom: two translational and one rotational. If we assume that the robot is moving on a planar surface, the translational coordinates are cartesian $(x, y)$, and the translational velocity is $v=\left(v_{x}, v_{y}\right)$. The horizontal orientation of the robot can be described by heading angle $\psi$. If we assume that the robot is not sliding, the same 3 degrees of freedom can be understood as arbitrary rotation in 3 -dimensional space, quantified by the angular velocity vector $\omega=\left(\omega_{x}, \omega_{y}, \omega_{z}\right)$. Please note that the angular velocity components are measured with respect to the global coordinates. The horizontal part of the angular velocity $\omega_{x y}=\left(\omega_{x}, \omega_{y}, 0\right)$ correlates with the translational velocity:

$$
v=\omega \times r=-\omega_{x y} \times\left(\begin{array}{lll}
0 & 0 & R
\end{array}\right)=\left(\begin{array}{lll}
-\omega_{y} R & \omega_{x} R & 0
\end{array}\right) .
$$

The vertical part of the angular velocity simply corresponds to the rate of the heading (yaw) angle:

$$
\frac{d \psi}{d t}=\omega_{z} .
$$

The orientation of the spherical robot (attitude) can be described by Euler angles. There are 12 possible conventions of them, but we use the Z-Y-X convention, widely used in aeronautics, and often referred to as Roll-Pitch-Yaw convention. Using this convention, along with NED ( $\mathrm{x}$-North, $\mathrm{y}$-East, $\mathrm{z}$-Down) axis orientation, the global angular velocity can be computed from the local angular velocity of the robot [28] (measured by an on-board gyroscope mounted on outer sphere):

$$
\omega=\underbrace{\left(\begin{array}{ccc}
c_{\Theta} c_{\psi} & s_{\varphi} s_{\Theta} c_{\psi}-c_{\varphi} s_{\psi} & c_{\varphi} s_{\Theta} c_{\psi}+s_{\varphi} s_{\psi} \\
c_{\Theta} s_{\psi} & s_{\varphi} s_{\Theta} s_{\psi}+c_{\varphi} c_{\psi} & c_{\varphi} s_{\Theta} s_{\psi}-s_{\varphi} c_{\psi} \\
-s_{\Theta} & s_{\varphi} c_{\Theta} & c_{\varphi} c_{\Theta}
\end{array}\right)}_{T} \cdot\left(\begin{array}{c}
\omega_{x} \\
\omega_{y} \\
\omega_{z}
\end{array}\right),
$$

where $\varphi, \Theta, \psi$ are roll, pitch, and yaw (Euler angles), respectively, and $s_{\varphi}=\sin \varphi, c_{\Theta}=\cos \Theta$, etc.

The goal of the robot's propulsion is to cause the robot's rotation. Possible actuation principles are described below.

\subsection{Direct Driving Method}

The direct driving method is designed in a simple manner. This mechanism transmits the motor torque directly to the outer shell as the driving force of the robot. This method requires a specially designed mechanism.

\subsubsection{Single Wheel}

A special mechanism (Figure 1) is used to control the SR with a single wheel. A. Halme et al. gave the first description of this method in 1996 at the University of Helsinki. The robot has one 
active wheel, being located inside the shell, along with an internal drive unit (IDU), together with a spring-loaded or fixed mechanism, ensuring constant contact with the inner shell [29]. The advantage of this mechanism is the easily adjustable speed of the SR determined by the speed of the motor wheel. The direction of the SR is controlled by turning the wheel.

The mechanism is one of the simple and low-cost platforms, but there are also many challenges posed. The problem emerges at high speeds, where slipping between the wheel and the inner shell of the SR might occur. This issue can be reduced by adjusting the spring tension between the spring-loaded system, IDU, and the wheel. Nevertheless, the friction force gradually increases, thus resulting in higher power consumption. Another issue with being rolling down is the well balanced design of this mechanism. Today, we do not see many SRs with this type of mechanism, since many of the issues mentioned above must be resolved [30].

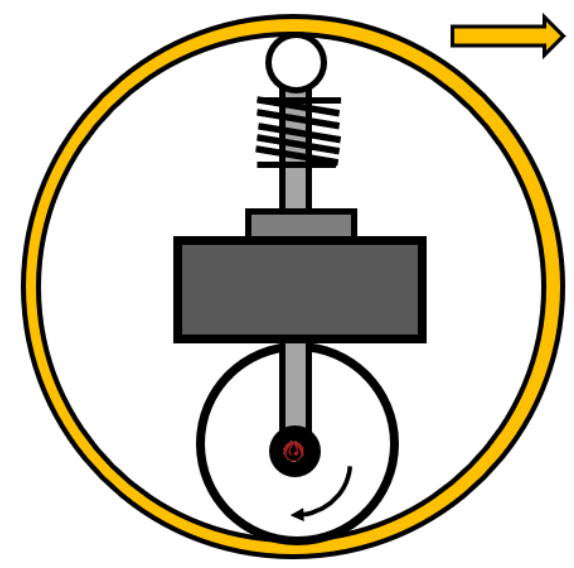

Figure 1. Principle sketch of a single wheel mechanism.

Later, in 2011, Q. Zhan described a project [31] having been based on the concept of a robot [29]. This team created a robot called BHQ-III, its name derived from the abbreviating Boltzmann-Hamel equation, and its creation is associated in a variety of ways with this equation. This mechanism consists of a single drive motor that is directly connected to the drive wheel. The drive wheel directly touches the inner shell of the SR, as in the previous case. Furthermore, the second motor is used to control the IDU, which directly controls the rotation of the robot. Undoubtedly, this principle ensures that the SR can move with an almost zero turning radius, accounting for a high degree of holonomy [31]. The primary advantage is that the platform touches the inner shell of the robot at 4 points, whilst onetouch is provided by the drive wheel, and the other 3 are provided by the sponge wheels, by means of which higher friction is achieved, and the robot can drive on uneven terrain.

\subsubsection{Hamster Ball}

This name in itself indicates what type of mechanism is used to control the SR. In most cases, a small-wheeled robot is placed in the ball as a remote-control car (Figure 2). Based on the movement of the remote-control car, the SR also moves. The first described SR of this kind was named SPHERICLE, and its mechanism was designed by A. Bicchii [32]. The internal robot was designed as a control unit with two wheels. The advantage of this type of driving mechanism is the ability to stop on a sloping surface, and, in line with this, it can roll down from it in a controlled manner. Several research teams have designed SRs on this principle, such as References [33-36]. Conclusively, these SRs differ from the design of the internal robot.

This type of driving mechanism cannot move holonomically, and its movement more resembles driving a car. The movement characteristic might change if the internal robot "hamster" uses a differential chassis or omnidirectional wheels [30,36,37]. As far as the 
movement characteristic is concerned, it also changes when the internal robot will be a controlled ball [35]. Hence, the SR can change direction immediately and has holonomic properties. The main disadvantage of this mechanism is the slippage and driving on uneven surfaces. If the internal robot jumps in the air, by chance, the SR becomes uncontrollable for a short time.

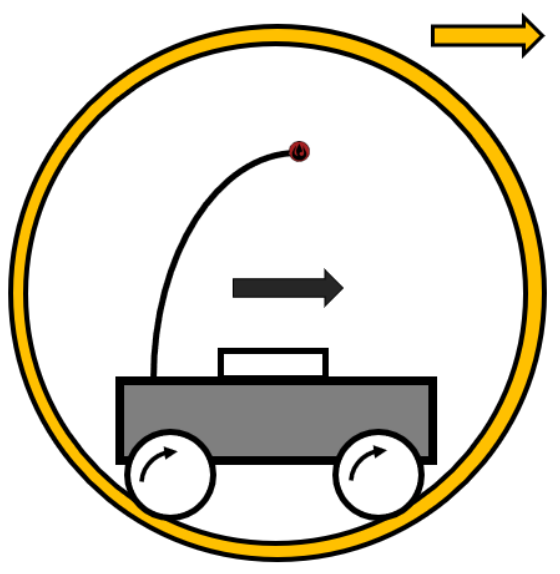

Figure 2. Principle sketch of a Hamster ball mechanism.

\subsection{The Gravity Driving Method}

The gravity driving method is based on a change of the Center of Mass (CoM), which creates torque that, in turn, drives the robot toward the desired direction.

\subsubsection{Shifting Masses}

R. Mukherjee et al. designed a new concept of the driving mechanism for SR called Spherobot [38]. The robot (Figure 3) disposes of a significant portion of its mass located in the geometric center of the shell. This SR requires, on the whole, minimum energy to spin the outer shell. In addition, the mechanism connects the geometric center with the inner shell of the robot using 4 shafts on which the masses are located. By moving these masses, the CoM of the robot changes, and the SR begins to roll [38].

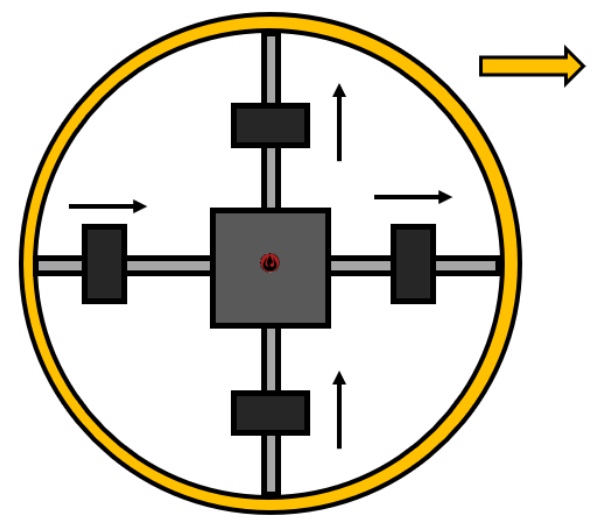

Figure 3. Principle sketch of a shifting masses mechanism.

Later on, this design was refined in References [39,40], by distributing the masses and shafts of the SR. It has the possibility, in conjunction with its design, to constantly accelerate, decelerate, and maintain a constant speed. 


\subsubsection{Pendulum}

The mechanism based on the pendulum principle is very popular today, with several SRs coupled with the principle emerging in References [3,17,41-47]. The principle is based on a shaft that is directly connected to the inner shell of the SR, and a pendulum that is connected in the middle of the shaft, which rotates around the shaft (Figure 4). By changing the position of the pendulum, the CoM is shifted, and SR begins to roll. Shifting the pendulum to the sides (right, left) causes shift of the CoM; hence, the SR will start rotating in the appropriate direction. F. Michauda and his team came up with this idea first, and they designed an SR with the name Roball [48]. This robot was designed as a children's toy. For simplicity of the model as a counterweight (pendulum), batteries were used, which are located at the bottom of the SR.

The disadvantage of this design being put forward is that the SR does not move holonomically, being manifested in a change of direction in a certain radius. There is a frail balance between the design of an SR with this principle and its internal components.

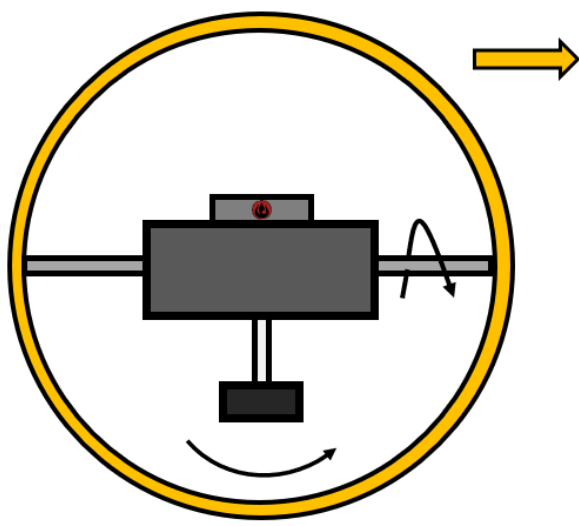

(a)

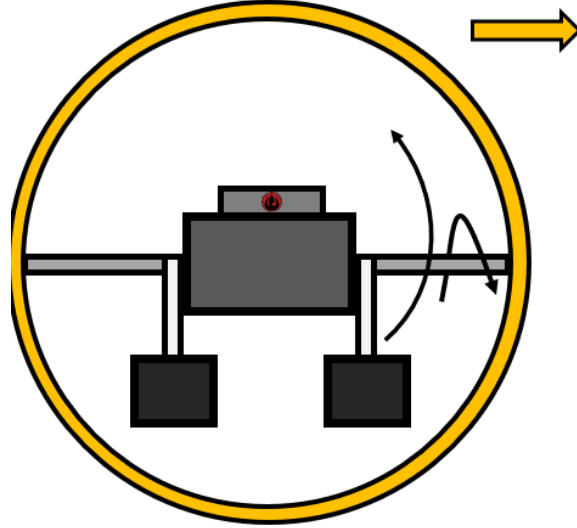

(b)

Figure 4. Principle sketches of a pendulum mechanism. (a) Single pendulum mechanism. (b) Double pendulum mechanism.

\subsubsection{Double Pendulum}

One of the similar mechanisms used two pendulums (Figure 4). B. Zho et al. came up with this idea, thus designing an SR with an elliptical shell $[49,50]$. The design interesting in that the robot can rotate in place. Based on this mechanism, other SRs were designed on a similar principle in References [51-55]. An interesting example of the use of a pendulum is Reference [56], where 4 pendulums are used for steering the SR.

Comparing the shifting masses method with a pendulum mechanism, the main differences are as follows. The shifting mass principle is holonomic, which means that the direction of movement can change immediately. However, the controls are more complicated because the main processor must keep real-time orientation data, as well as distance data of all masses. Another disadvantage of the original design proposed in Reference [38] is the slow change of position of the mass, causing slow movement. This problem is solved in Reference [57], where the authors propose a robust higher order sliding mode controller. A second order super twisting sliding mode controller can attain the desired trajectory, as well as improve the performance of the typical non-linear robust controller. This sliding mode controller proves that the proposed controller can reduce control chattering and achieve robust operation in the presence of external disturbances and model uncertainties, as well. The authors use a super twisting algorithm to drive the error and its derivative to zero for asymptotic convergence. 


\subsubsection{Gimbal Mechanism}

M. Kabał et al. designed the SR Roball in Reference [58], which was controlled by a new type of driving mechanism, i.e., the gimbal mechanism (Figure 5). Later, in 2006, a team led by Y. Ming changed the configuration of the gimbal robot and built a new SR with the name HIT [59]. The mechanism is designed in a way that the steering and driving mechanisms are independent of each other. The SR combines two motors, one for rotating the IDU in a circular path inside the shell of the SR, and the other for movement. The mechanism for moving forward/backward and the turning mechanism are self-dependent, which means HIT has non-holonomic properties. Several robots have been designed using this principle, such as BYQ-III, in Reference [60], and others, in References [53,61-63].

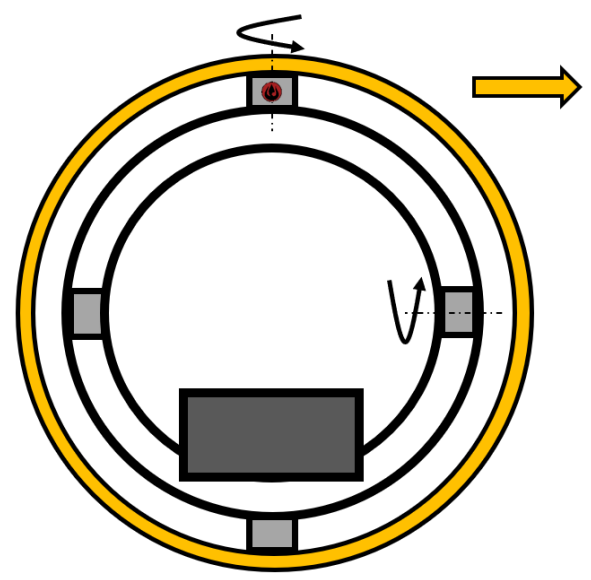

Figure 5. Principle sketch of a gimbal mechanism.

\subsubsection{Dynamics}

The displacement of the robot's centrum of gravity is:

$$
\tau=\frac{m}{M} x,
$$

where $m$ is the weight of the moving mass, $M$ is the overall mass of the robot, and $x$ is the horizontal displacement of the moving mass with regard to the robot's geometrical centrum.

The maximal torque of the robot is:

$$
T=M q(\tau-\xi),
$$

where $g$ is the gravitational acceleration, and $\xi$ is the rolling resistance arm.

The SR driven by CoM shifting is capable to maintain speed up to:

$$
v_{\max }=\min \left(2 \pi \kappa f_{\max } R, \frac{P_{\max }}{M g\left(\frac{\xi}{R}+\sin \Theta\right)}\right),
$$

where $f_{\text {max }}$ is the maximal speed (in rotations per second) of the driving motor, $\kappa$ is the effective gear ratio between the motor and the ball (moving mass), $R$ is the outer radius of the robot, $P_{\max }$ is the maximal constant output power of the motor, and $\Theta$ is the slope of the terrain.

The maximal slope of the terrain on which the CoM-shifting SR may stand still is:

$$
\Theta_{\max }=\min \left(\arcsin \left(\frac{\tau_{\max }}{R}\right), \arctan (\mu)\right),
$$

where $\mu$ is the static friction coefficient between the SR surface and the terrain surface, and $\tau_{\text {max }}$ is the maximal displacement of the robot's CoM. If we assume the inner structure of 
the directly-driven SR (see Section 2.2) does not rotate inside the robot, the same formulas are valid as in the case of CoM-shifting.

\subsection{The Angular Momentum Driving Method}

Another way used to control SRs is using the control moment gyroscopes (CMG). By spinning the flywheel and then rotating it around the axis of the robot, one might control the SR based on maintaining the angular momentum. As the CMG angular velocity increases, the torque also increases. A unique feature of using a CMG is that these systems have reaction forces in all three spatial dimensions. Specifically, if a CMG is spinning around the $\mathrm{X}$-axis and is rotated about the Y-axis, then there will be a torque around the Z-axis. Many robots have been designed on this principle, such as in References [23,64-66].

$\mathrm{S}$. Bhattacharya et al. designed the first SR which used angular momentum to move [67]. The SR includes two pairs of orthogonally mounted motors (Figure 6), which are connected to the shell. As a result, the shell rotates in exactly the opposite direction to that of the motor. The individual motor spins with respect to the vertical and horizontal axes of the ground, and in this way, it is possible to control the movement and direction of the SR. The advantage of this mechanism is that the SR can move holonomically. SRs designed based on similar principles are proposed in References [68-70].

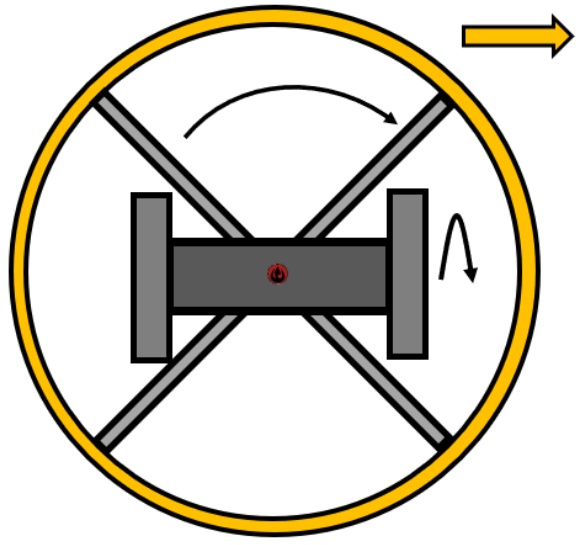

(a)

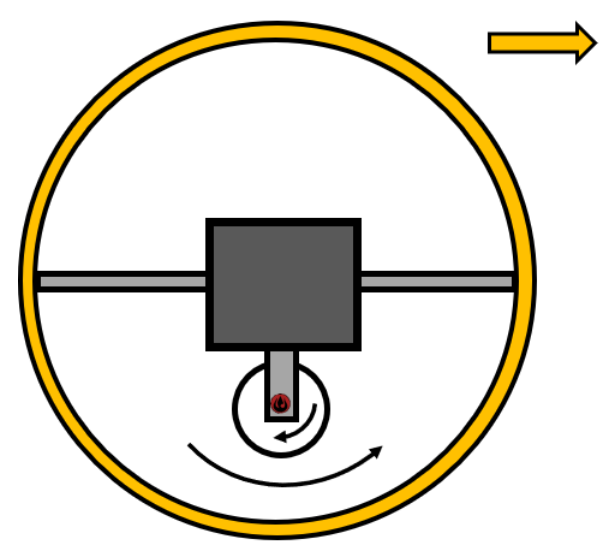

(b)

Figure 6. Principle sketches of an angular momentum driving method. (a) Mechanism of orthogonally mounted motors. (b) Flywheel mechanism.

The SR with one flywheel was designed by G. Shu [71]. The SR was designed on the principle of a pendulum, but, instead of a mass, a flywheel was placed on the pendulum (Figure 6). An acceleration or deceleration of the CMG causes the SR to start rotating. In special conditions, an SR with this type of mechanism can have a holonomy property. In 2009, an SR with one flywheel was designed on a similar principle in Reference [71]. This SR was designed by Q. Jan et al. and named BHQ-5 [72]. The rationale behind it was to use a flywheel on the pendulum. With the CMG placed where the mass of the normal pendulum system would be, the SR can rotate itself, depending on how the CMG rotates. Furthermore, depending on the orientation of the CMG and how it is moved, it can also increase the angular momentum of the SR, as well, providing more torque than that which would be provided by just a normal pendulum and mass.

J. Chen et al. designed an SR with two flywheels, in Reference [73], on a similar principle as that presented in Reference [71]. This means that the SR was able to overcome much sharper slopes than all other SRs and, at the same time, had high stability.

Dynamics

The torque of the robot with regard to surface is: 


$$
T=\min \left(J \frac{d \omega}{d t}, \mu M g R \cos \Theta\right),
$$

where $J$ is the momentum of inertia of the flywheel, and $\frac{d \omega}{d t}$ is its angular velocity rate. If a very powerful motor is used to drive the flywheel, the only limit of the robot's torque (hence its acceleration) is the friction between the ball surface and the surface of the terrain. It allows for achievement of lower response time of the robot's motion control. The dynamics of the robot can be simplified into the following equation:

$$
\left(M R^{2}+J_{R}\right) \frac{d v}{d t}=T-M g \xi,
$$

where $J_{R}$ is the momentum of inertia of the robot, excluding the flywheel. If we assume the maximal speed is achieved when maximal torque is applied, the maximal short-time speed of the robot on a horizontal surface is:

$$
v_{\max }=\left.\frac{d v}{d t}\right|_{T_{\max }} \cdot \frac{\omega_{\max }}{\frac{\mu M g R}{J}}=\frac{J \omega_{\max }(\mu R-\xi)}{\mu\left(M R^{2}+J_{R}\right)},
$$

where $\omega_{\max }$ is the maximal angular velocity of the flywheel. On the other hand, the robot is not capable to maintain constant speed in the case of constant rolling resistance because it would require infinite speed of the flywheel. The maximal time the momentum-driven $\mathrm{SR}$ is capable of staying still on a sloped surface is:

$$
t_{\text {hold }}=\frac{\omega_{\max }}{\frac{d \omega}{d t}}=\frac{J \omega_{\max }}{M g \cdot \max (R \sin \Theta, 0)} .
$$

If the rolling resistance arm $\xi$ exceeds the term $R \cdot \sin \Theta$, the robot is capable of staying still on the a small slope without actually rotating the flywheel.

\subsection{Some Other Types of Driving Mechanisms}

SR can also be controlled by a change of the surface structure. M. Srtus et al. designed an SR, which moved by deforming the outer shell [74]. The outer shell consisted of 4 sections of dielectric elastomeric sections, which can be transformed by an electric field. Transformation of the sections in sequence will cause the robot to roll. Later, K. Wait et al. designed an SR, presented in Reference [75], which improved the idea of Reference [74]. The robot closely resembled a football and moved by inflating and deflating individual air segments (Figure 7). Depending on which segments are filled with air, it is possible to move the ball on an accurate path. This type of system can provide holonomic motions.

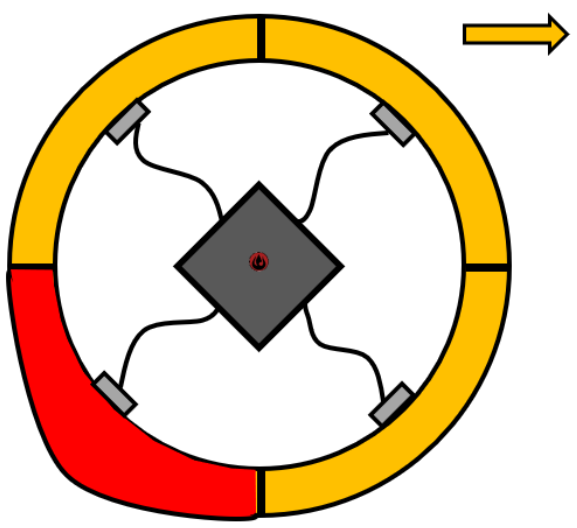

Figure 7. Principle sketch of deforming the outer shell.

Another possibility for the SR to move is a hybrid mechanism that allows the SR to roll or walk. One of the designs was performed by S. Mahboubi, who designed an SR with four 
legs [76]. This design was improved by T. Aoki, who designed a fully hybrid SR [77] called QRoSS, originally designed as a reconnaissance robot (Figure 8). It has the possibility of rolling on a flat surface, and, in the case of an uneven surface or an obstacle, it will extend its legs, and the robot will overcome the given unevenness. A similar proportion of hybrid robots can operate on a similar principle, such as in References [78-80].

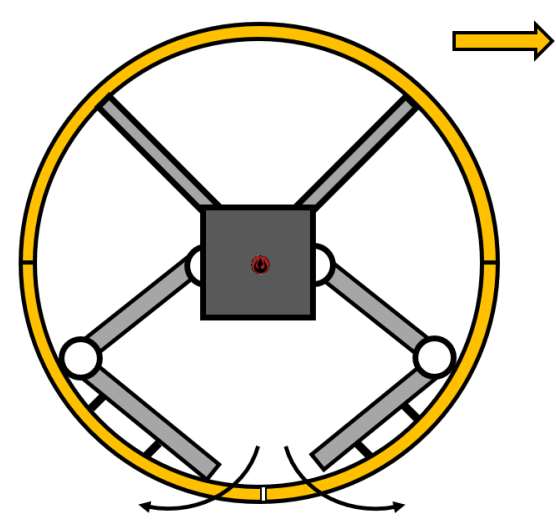

Figure 8. Principle sketch of a hybrid SR.

Dynamics

Deformation of the outer shell basically shifts the point of contact between the surface of an SR and the terrain. Such a shift has the same effect as CoM-shifting. We may estimate the shift of the contact point as shown in Figure 9, assuming the centrum of gravity will stay in the center of the robot:

$$
\tau=\sqrt{(R+\Delta R)^{2}-R^{2}}=\sqrt{2 R \Delta R+\Delta R^{2}},
$$

where $\Delta R$ is the local increase of the outer shell radius caused by deformation. The deformation allows greater $\tau$ than mass-shifting, e.g., when $\Delta R>R(1-\sqrt{2})$, the contact point is outside the radius of the robot.

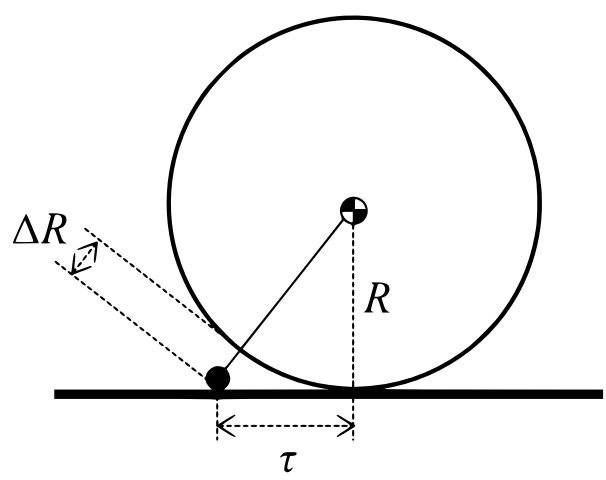

Figure 9. Shift of the contact point.

\subsection{Comparison of Each Mechanism}

Each of the methods has both pros and cons. When we focus on the driving characteristic of the direct driving method, the torque of the motor is transmitted directly to the robot shell, as mentioned above. This force is comparable to the gravity method with gravity focus. The forces can be increased, which makes it possible for the SR to increase the speed of movement and, thus, overcome obstacles on the part of the robot. The angular momentum driving method uses a large kinetic force. Because a balance of momentum is needed, control is quite difficult; therefore, it is necessary to plan the trajectory of the robot.

Considering the driving capability, one of the most important characteristics is omnidirectional mobility since it is a unique feature of an SR, as described in the first paragraph. 
Omnidirectional mobility (holonomy), in particular, according to its definition, indicates that the robot can move in any direction at any moment, using degrees of freedom (DoF) for movement.

An SR that uses the gravity driving method can move holonomically, but trajectory planning is more difficult. The reason is that the orientation and movement of the SR are based on a continuous change of CoM using the masses. Additionally, the construction of such an SR is fairly demanding. A simple definition of holonomy is the ability to make sharp turns at any time.

However, the power of an SR with these two methods is limited because the CoM cannot be moved outside of the shell.

SRs with flywheels are not able to achieve omnidirectional holonomies because the direction of the momentum changes gradually, for which gradual change of direction is obvious.

Table 1 shows a brief comparison of some types of driving mechanisms of SRs.

Table 1. An overview of applied SR mechanisms in existing papers.

\begin{tabular}{llll}
\hline Mechanism & Driving & Holonomy & Use \\
\hline Single wheel & $\mathrm{D}$ & - & References [29-31] \\
Hamster ball & $\mathrm{D}$ & $\mathrm{v} *$ & References [32-36] \\
\hline Mass movement & $\mathrm{G}$ & $\mathrm{v}$ & References [38-40] \\
Pendulum & $\mathrm{G}$ & $\mathrm{v} *$ & References [3,17,41-47] \\
Gimbal mechanism & $\mathrm{G}$ & $\mathrm{V} *$ & References [58-63] \\
\hline Orthogonal flywheels & $\mathrm{M}$ & $\mathrm{V} *$ & References [67,69,70] \\
Flywheel on pendulum & $\mathrm{M}$ & - & References [71-73] \\
\hline Deformation & $\mathrm{O}$ & $\mathrm{v}$ & References [74,75] \\
Hybrid & $\mathrm{O}$ & $\mathrm{V} *$ & References [76-80] \\
\hline
\end{tabular}

$\mathbf{D}$ indicates the direct driving method, $\mathbf{G}$ indicates the gravity driving method, and $\mathbf{M}$ indicates the angular momentum method. $\mathbf{v}$ indicates that the robot is able to perform a specific movement, and $\mathbf{v} *$ or number $*$ indicates that the robot can perform the movement in specific conditions.

Table 2 shows a functional feature comparison of some types of driving mechanism of SRs.

Table 2. Comparison of functional features of SRs driving mechanism.

\begin{tabular}{lllllll}
\hline Mechanism & CDoF & Mobility & $\begin{array}{l}\text { Maneuve- } \\
\text { Rability }\end{array}$ & Stability & $\begin{array}{l}\text { Dead } \\
\text { Reckoning }\end{array}$ & Design \\
\hline $\begin{array}{l}\text { Single wheel } \\
\text { Hamster ball }\end{array}$ & 2 & Good & Weak & Weak & Wimple \\
Great & Good & Geak & Weak & Difficult \\
\hline $\begin{array}{l}\text { Mass } \\
\text { movement }\end{array}$ & 3 & Great & Good & Great & Good & Average \\
$\begin{array}{l}\text { Pendulum } \\
\begin{array}{l}\text { Gimbal } \\
\text { mechanism }\end{array}\end{array}$ & $2 *$ & Good & Great & Great & Great & Difficult \\
\hline $\begin{array}{l}\text { Orthogonal } \\
\text { flywheels }\end{array}$ & 2 & Good & Good & Good & Good & Difficult \\
$\begin{array}{l}\text { Flywheel on } \\
\text { pendulum }\end{array}$ & 3 & Great & Good & Good & Good & Average \\
\hline $\begin{array}{l}\text { Deformation } \\
\text { Hybrid }\end{array}$ & 3 & Great & Great & Good & Good & Difficult \\
\hline
\end{tabular}




\section{Inertial Sensors}

In order to estimate the attitude and direction (3-DoF rotation) of the spherical robot, inertial sensors need to be installed onboard the robot. The rotation of the robot can be expressed by several structures, including:

- Quaternion:

$$
q=\left(\begin{array}{llll}
w & x & y & z
\end{array}\right)=\left(\begin{array}{llll}
\cos \vartheta & n_{x} \sin \vartheta & n_{y} \sin \vartheta & n_{z} \sin \vartheta
\end{array}\right),
$$

where $\left(n_{x}, n_{y}, n_{z}\right)$ are the coordinates of unit vector expressing arbitrary axis of rotation and is the angle of rotation around that axis.

- Rotation matrix T: with dimensions $3 \times 3$, which defines the transformation between the robot's local coordinate system and the global coordinate system, or vice versa.

- Euler angles: a sequence of 3 rotations around fundamental axes of the robot's coordinate system, e.g., Z-Y-X, named yaw $\Psi$, pitch $\Theta$, and roll $\varphi$.

The rotation of the robot can be measured by a gyroscope. There are 4 working principles:

- Mechanical rotating gyroscope: may directly measure the attitude of the robot. The oldest type, widely used in aircraft and missile control systems. It is based on the principle that the attitude of a flywheel in a gimbal is maintained regardless of the orientation of the robot or aircraft itself. The main disadvantages are larger dimensions and mass, higher power consumption needed to rotate the flywheel, and higher price. Hence, it can be used only on large robots [81].

- $\quad$ Ring laser gyroscope (RLG): estimates the angular velocity of the robot's rotation around one axis and is based on the Sagnac effect. It measures the phase shift between two beams of light, traveling in opposite directions in loop formed by multiple mirrors. The phase shift is proportional to the area of the loop A and the angular velocity of the rotation perpendicular to the area:

$$
\Delta \Phi \approx \frac{8 \pi}{\lambda c}(\omega \cdot \mathbf{A}),
$$

where $c$ is the speed of light, and $\lambda$ is its wavelength. RLGs are very precise but have large dimensions in order to keep the area of the loop as large as possible [82].

- Fiber optic gyroscope (FOG): works on the same principle as RLG but uses an optic fiber to guide the light around the loop. The fiber can be coiled into multiple turns, which multiplies the effective area of the loop, thus increasing the sensitivity of the sensor, while keeping the dimensions small. These gyroscopes are replacing the mechanical ones in both aviation and military technologies. The main disadvantage of FOG is the high price, rendering it costly to deploy in small, single-use robots $[83,84]$.

- MEMS vibrating structure gyroscope: estimates the angular velocity of the robot's rotation around single axis by measuring the Corriolis force affecting a vibrating mass. The main advantages are the small dimensions, low power consumption, and low cost, thanks to the MEMS (Micro Electro-Mechanical System) technology, which allows their usage in small, low-cost robots and mobile devices. MEMS gyroscopes have significantly lower precision than RLGs and FOGs [85].

If an FOG, RLG, or MEMS gyroscope is used in a spherical robot, three independent axes of rotation have to be measured. Many manufacturers provide 3 sensors oriented perpendicular to each other in single sensor module. The readings of the angular velocity need to be integrated to obtain the absolute rotation (expressed as quaternion, rotation matrix, or Euler angles). It results in increasing error of the estimated rotation [86]. This gradually increasing error can be compensated toward some constant level by using accelerometer and magnetometer to obtain the absolute Euler angles with respect to the horizontal: North orientation.

The accelerometer measures the sum of the linear acceleration of the object and gravity acceleration: 


$$
\mathbf{a}_{a c c}^{\prime}=\mathbf{a}_{\text {robot }}^{\prime}+\mathbf{g}^{\prime} .
$$

The acceleration of the spherical robot can usually be neglected with respect to the gravity acceleration. The roll and pitch angles (Z-Y-X Euler convention) can be computed from acceleration as:

$$
\begin{gathered}
\Phi_{a c c}=\operatorname{atan} 2\left(-a_{y}^{\prime},-a_{z}^{\prime}\right), \\
\Theta_{a c c}=\operatorname{atan} 2\left(a_{x}^{\prime}, \sqrt{a_{y}^{\prime 2}+a_{z}^{\prime 2} .}\right.
\end{gathered}
$$

There are 3 main types of accelerometers:

- Piezoresistive accelerometers: are simple, low-cost and DC-responsive devices that can measure constant acceleration, such as gravity. The major drawbacks of piezoresistive sensing are the temperature-sensitive drift and the lower level of the output signals. The sensing element consists of a cantilever beam, and its proof mass is formed by bulk-micro-machining. The motion of the proof mass due to acceleration can be detected by piezoresistors in the cantilever beam and proof mass. The piezoresistors are arranged as a Wheatstone bridge to produce a voltage proportional to the applied acceleration $[87,88]$.

- Piezoelectric accelerometers: do not respond to the constant component of accelerations. In a piezoelectric accelerometer, the sensing element bends due to applied acceleration, which causes a displacement of the seismic mass, and results in an output voltage proportional to the applied acceleration [89].

- Differential capacitive accelerometers: have low power consumption, large output level, and fast response to motions. The displacement of the proof mass can be measured capacitively. In a capacitive sensing mechanism, the seismic mass is encapsulated between two electrodes. The differential capacitance is proportional to the deflection of the seismic mass between the two electrodes. Better sensitivity is also achieved due to the low noise level of capacitive detection. Differential capacitive accelerometers also have DC response. Currently, this kind of accelerometer has widely been used in most applications, especially in mobile and portable systems and consumer electronics [90,91].

The 3-axis magnetometer (magnetic compass) allows for estimation of the direction of the robot from the measured magnetic induction vector

$$
\psi_{m a g}=\operatorname{atan} 2\left(-B_{y}, B_{x}\right),
$$

where $B_{x}$ and $B_{y}$ are the components of the magnetic induction vector in global coordinates, which can be computed from measured vector $\left(B_{x}^{\prime}, B_{y}^{\prime}, B_{z}^{\prime}\right)$ :

$$
\begin{gathered}
B_{x}=B_{x}^{\prime} \cos \Theta+B_{y}^{\prime} \sin \Phi \sin \Theta+B_{z}^{\prime} \cos \Phi \sin \Theta, \\
B_{y}=B_{y}^{\prime} \cos \Phi-B_{z}^{\prime} \sin \Phi .
\end{gathered}
$$

So far, different types of magnetic field sensors, such as Hall sensors, semiconducting magnetoresistors, ferromagnetic magnetoresistors, fluxgate sensors, superconducting quantum interference device (SQUID), resonant sensors, inductive magnetometers, etc., have been developed for various applications. In the following sections, these types of magnetic field sensors are discussed:

- Hall sensors: are based on the Hall effects. These sensors alter its output voltage in relation with the magnetic field. More than $90 \%$ of all magnetic field sensors are Hall sensors. Hall sensors are used in proximity switching, positioning, speed detection, and current sensing applications [92,93].

- Semiconductor magnetoresistors: change their electrical resistance in response of external magnetic field. Though semiconductor magnetoresistors are less common 
than Hall sensors. Modern semiconductor magnetoresistors are fabricated as a serial connection of many miniature elements on one chip. The main disadvantage of these sensors is their quadratic characteristics, which does not allow their use in small fields. Both magnetoresistors and Hall sensors are sensitive to the magnetic field perpendicular to the surface [94].

- Ferromagnetic Magnetoresistors: can be classified as anisotropic magnetoresistance (AMR)-, giant magnetoresistance (GMR)-, and spin-dependent tunneling (SDT)-based sensors [95].

- Fluxgate sensors: are classical precise sensors developed in the 1930s. They can measure DC and low-frequency AC fields. Fluxgates are expensive, bulky, and powerconsuming devices [96,97].

- Superconducting Quantum Interference Device (SQUID): are based on superconducting Josephson junction and flux antenna. These extremely sensitive devices measure magnetic field changes, rather than absolute field value. SQUIDs today are used for biomagnetic experiments and for measurement of magnetic properties of samples that are small or magnetically very weak [98].

- Resonant magnetometers: measure the total field value (scalar), rather than its vector. This means that the reading is not dependent on the field direction (with the exception of possible dead zones). This may be an advantage in cases when the directional information is not required, or it can be derived using other sensors. In such cases, the field measurement is easy, as the direction of the sensor head is arbitrary. The main advantage of resonant magnetometers is that they are absolute instruments with very small uncertainty. The disadvantage of resonant magnetometers is that they usually have limited field range, and they fail at small fields [99,100].

- Induction magnetometers: are based on the Faraday induction law, which means that the voltage sensitivity is proportional to the frequency [101,102].

There are multiple sensor fusion techniques for a gyroscope + accelerometer + magnetometer system, which is usually a variation of extended Kalman filter or complementary filter [86].

\section{Sensor Equipment}

As we mentioned in Section 1, the following sensors can extend the possibilities of the SR. The sensors were specified in Reference [1], and the same sensors were specially designed for the intended purpose of reconnaissance, during emergencies in road tunnels or during a traffic accident.

We will deal with cameras in the visible spectrum and IR spectrum. These cameras can be used for visual monitoring space around the robot. In addition, we will deal with gas and temperature sensors. These sensors can determine the state of the environment. Lastly, the described sensor will be LiDAR, which is appropriate for scanning the environment and making a 2D map, as well as might be used for precise obstacle detection.

\subsection{Cameras (Smallest and Low-Cost)}

The main topic is to determine the smallest possible camera with sufficient resolution with the most acceptable cost for use in our application.

The image capture device may be a CCD-based camera, or a CMOS-based one. In principle, CMOS devices are smaller and cheaper than CCD cameras, but the quality of CMOS images is not as good as with a CCD camera. In general, better image resolution means a larger image size and higher processing and transmission performance. The trade-off between the quality of visual data and the consumption of system resources depends on the requirements of the application. For applications that require higher image quality (e.g., face recognition as part of security surveillance), a CCD camera is a better choice. For applications that require to capture a large number of images do not require high resolution (such as tracking objects in the wild), CMOS is a better choice. In addition 
to the requirements of the application, the chosen device depends on the trade-off between price, size, measuring spectrum, energy consumption, and the resolution of the visual data.

Our research focused primarily on CMOS cameras, due to the fact that it is not necessary to use high-resolution images, and the price is lower than CCD cameras.

\subsubsection{Cameras Operating in the Visible Spectrum}

A large number of mini cameras operate in the visible spectrum. In Reference [103], the OV9655 scanner was used as a barcode scanner, and, in Reference [104], the scanner in a wireless network was used, due to its low energy consumption.

W. Song et al. developed a survey robot presented in Reference [105] that is used to inspect cable tunnels. They used the OV7670 CMOS sensor for this application. The sensor was chosen for its small size and low power consumption. However, with the exception of the ideal conditions, the design for real conditions would still require further adjustments. Another interesting application was presented in Reference [106], where gestures were sensed using the mentioned camera sensor and subsequently recognized by the FPGA. Alternatives are proposed in other implementations in References [107,108].

An interesting area of use of mini cameras is the creation of wireless networks to capture a certain area. W. Qi et al. created an intelligent home video surveillance presented in Reference [109], where they designed a wireless monitoring system. In this case, they used the OV2640 camera. Mini cameras are also quite frequently used in healthcare, namely in endoscopy and laparoscopy, where the effort is to provide the smallest possible tools for intervention in the human body. Thus, Y. Zhang et al. created a capsule endoscope [110]. This endoscope uses wireless image transmission, where the aforementioned camera element was used.

Another frequently used camera is named MT9M001. In 2011, it was used in highspeed image processing [111]. A team led by L. Qin created a system for high-speed image detection and processing. This system is typically used in photoelectric tracking or communication with a space laser. In the field of biomedicine, this sensor has been used as part of an optical demographic system [105]. The camera was used to increase the accuracy of particle size detection. Alternatively, in Reference [112], it was a component in X-ray spectroscopy.

\subsubsection{IR Cameras}

Infrared radiation is often confused with thermal radiation (according to the sensitivity of the human body), but the fact is that the surfaces of bodies emit almost all types of electromagnetic radiation. However, it is true that objects at room temperature emit the most radiation in the IR band 8-12 $\mu \mathrm{m}$. From about $700{ }^{\circ} \mathrm{C}$, heat radiation, at wavelengths, is visible to the human eye. Colors range from "dark glow" to dark red, red, and yellow to white.

A. Gecza et al. created a car passenger detector based on an infrared camera [113]. They used a small and low-cost infrared camera called AMG8833 for this experiment. The position of the sensor, the resolution, the ambient temperature, and many aspects were taken into account, as the camera has certain limitations. The camera was validated in a laboratory environment at room temperature, where it was possible to distinguish a person from the background. Four basic positions were considered in the car, with people being able to sit in the front or rear seats, or more (0-5 people) at the same time. The result of the work was to point out that it is possible to detect passengers in the vehicle even with a cheap solution. In addition, in 2020, during the COVID-19 pandemic culmination, non-contact temperature measurement became more and more common. V. Ionescu et al. created an overview of low-cost thermal sensors, where, in Reference [114], they also mention the aforementioned camera. Alternatively, this type of sensor has been reported in patient monitoring that respects patient privacy $[115,116]$.

Another area of using infrared cameras is in the design of an intelligent air cooler system [117]. P. Du designed this proposal, together with his team, where they used an 
infrared camera MLX90640. Using an infrared camera, they detect an area of uneven heat dissipation and, in turn, create a temperature grid based on the image. At the same time, the camera was also used for temperature calculation methods for electrical equipment [118]. They point out a demand for monitoring the temperature of electrical machines because, when the temperature rises too high, it is likely to cause serious accidents.

\subsubsection{Comparison of Camera Sensors}

The following, Table 3, summarizes all used sensors, together with their basic properties.

Table 3. Review of cameras with main properties.

\begin{tabular}{|c|c|c|c|c|c|c|}
\hline Spectrum & Label & $\begin{array}{l}\text { Resolution } \\
\text { [MP] }\end{array}$ & Pixels $(\mathrm{W} \times \mathbf{H})$ & $\begin{array}{c}\text { Maximum } \\
\text { Image Rate } \\
\text { [fps] }\end{array}$ & $\begin{array}{c}\text { Power } \\
\text { Consumption } \\
{[\mathrm{mW}]}\end{array}$ & Use \\
\hline \multirow{4}{*}{ Visible } & OV9655 & 1.3 & $1280 \times 1024$ & $15-30$ & 90 & $\begin{array}{c}\text { References } \\
{[103,104,119]}\end{array}$ \\
\hline & OV7670 & 0.3 & $640 \times 480$ & 30 & 60 & $\begin{array}{c}\text { References } \\
{[105-108,120]}\end{array}$ \\
\hline & OV2640 & 2 & $1632 \times 1232$ & $15-60$ & $125-140$ & $\begin{array}{l}\text { References } \\
{[109,110,121]}\end{array}$ \\
\hline & MT9M001 & 1.3 & $1280 \times 1024$ & 30 & 325 & $\begin{array}{c}\text { References [111, } \\
112,122,123]\end{array}$ \\
\hline \multirow{2}{*}{ IR } & AMG8833 & $64 \times 10^{-6}$ & $8 \times 8$ & $1-40$ & 15 & $\begin{array}{c}\text { References } \\
{[113-115,124]}\end{array}$ \\
\hline & MLX90640 & $764 \times 10^{-6}$ & $32 \times 32$ & 64 & 83 & $\begin{array}{l}\text { References } \\
{[116-118,125]}\end{array}$ \\
\hline
\end{tabular}

\subsection{Gas Sensors (Smallest and Low-Cost)}

The main idea is to establish which are the smallest possible gas sensors with sufficient accuracy and low cost.

In enclosed spaces with little possibility of ventilation, or during a traffic accident in the tunnel, it is inevitable to know the concentration of dangerous gases in the air. In conjunction with this, prolonged exposure to a hazardous gas in a closed room can result in permanent damage to human health or even death. Therefore, the robot will read the values of $\mathrm{CO}_{2}$ (Carbon dioxide) and $\mathrm{CO}$ (carbon monoxide) concentrations. Table 4 , below, shows the given concentration intervals of individual gases and their consequences [42,126].

When measuring gases concentration, such as carbon dioxide, oxygen, or methane, the term concentration is used to describe the amount of gas by volume in air. The two most common units of measurement are parts per million and percent concentration. Parts per million (ppm) is the ratio of one gas to another. For example, $1000 \mathrm{ppm}$ of CO means that, if we could count a million molecules of gas, 1000 of them would be from carbon monoxide, and 999.000 molecules would be some other gas. 
Table 4. Overview of the concentration and its consequences on the human body.

\begin{tabular}{cccc}
\hline & \multicolumn{2}{c}{ CO } & \\
\hline Concentration [ppm] & Effect & Concentration [ppm] & Effect \\
\hline$\leq 1000$ & $\begin{array}{c}\text { None (standard air } \\
\text { value) }\end{array}$ & 100 & Mild headache \\
\hline $1000-2000$ & $\begin{array}{c}\text { Drowsiness, slight } \\
\text { difficulties }\end{array}$ & $200-300$ & Headache \\
\hline $2000-5000$ & $\begin{array}{c}\text { Headache, loss of } \\
\text { concentration }\end{array}$ & $400-600$ & $\begin{array}{c}\text { Severe headache, } \\
\text { nausea }\end{array}$ \\
\hline 5000 & $\begin{array}{c}\text { Severe headache } \\
\text { unconsciousness }\end{array}$ & $1100-1500$ & $\begin{array}{c}\text { Increased pulse, } \\
\text { fainting, } \\
\text { unconsciousness }\end{array}$ \\
\hline 40,000 & Suffocation & $5000-10,000$ & $\begin{array}{c}\text { Weak pulse, } \\
\text { respiratory arrest }\end{array}$ \\
\hline
\end{tabular}

\subsection{1. $\mathrm{CO}_{2}$ Sensors}

Domestic air monitoring stations, measuring mainly carbon dioxide, are largely made from cheap gas detectors. From Table 4, we can see that, if there is good air quality in the room, people can then be fully focused on their chores. In Reference [127], a dangerous gas sensor was designed using the MQ-135 sensor $[128,129]$, which also included other dangerous gases. Alternatively, in Reference [130], the author created a simple detector of $\mathrm{CO}_{2}$ and $\mathrm{CO}$ based on the aforementioned sensor and displayed the resulting value on a display in ppm. When exceeding the limits, the system triggers an alarm in the form of a buzzer noise.

A similar work was created in the LabVIEW platform. In Reference [131], in 2020, the author created a home alarm, which also contained a $\mathrm{CO}_{2}$ sensor, MQ-135. The system can monitor the following parameters: temperature, gas concentration, and the presence of smoke due to fire, as well as an audible warning when exceeding normal values. Reference [132]'s work was created in the given tool, which uses a sensor of the MG-811 series for $\mathrm{CO}_{2}$ sensing [133]. Online solutions for monitoring environmental parameters using Internet of Things (IoT) techniques help to collect values of parameters, such as $\mathrm{pH}$, temperature, humidity, and $\mathrm{CO}_{2}$ concentration. The use of sensors allows intensive control of environmental pollution caused by industrial manufacturing. Reference [132] deals with the control of pollution caused by the untreated disposal of waste. In the measurement of air pollution in Reference [134], the author uses the sensor MQ-135 for sensing ambient gases around the landfill. The scholar designed a platform based on gas sensors to monitor the surrounding gases from solid waste repositories using a given mobile phone sensor. A similar work with the same sensor was focused on sanitary landfills [135]. The authors dealt with two parameters for this type of landfill. Groundwater quality and greenhouse gas concentrations were measured simultaneously. The data from the sensors are sent to the cloud, where they are processed. If the limit value is exceeded, an SMS will be sent.

Recently, A. Gecza et al. created a prototype for measuring air quality [136]. They created a low-cost prototype for air quality monitoring that is small in size, easy to use, and compatible with a smartphone. The prototype was tested on the streets of Budapest. Alternatively, there is the possibility of using the facility in connection with the COVID-19 pandemic. In relation to air quality in hospitals, a proposal for a low-cost air quality monitor has been developed [137]. Table 4 illustrates reduced air quality results in headaches, fatigue, and lack of concentration. The hospital also works with a number of chemicals that can degrade air quality. At the same time, with a large number of people in a small space, therefore, it is necessary to constantly monitor the air quality. Reference [137] introduces a cheap variant of a monitoring device with a CCS811 sensor [138]. Alternatively, there are similar papers about air quality measurement; for example, see Reference $[129,139,140]$. 
In 2020, a mobile robot was created by M. Evit et al. to monitor a volcano [141]. The mobile robot was designed in Indonesia, as they are in the Pacific ring of fire and have a total of 129 active volcanoes. If an eruption occurs on a volcano, the current fixed monitoring system is not completely reliable. On the other hand, monitoring of other volcano activities is critical in this situation. Therefore, there is a need for a volcano monitoring system that can move freely and operate safely. When creating a mobile robot, we used the $\mathrm{MG} 11 \mathrm{CO}_{2}$ sensor, as well as a number of other sensors.

\subsubsection{CO Sensors}

The measurement of $\mathrm{CO}$ is largely performed in the determination of air quality with the help of AQI (Air Quality Index). Thus, a large amount of work deals with the creation of a low-cost platform for measuring AQI, which also includes the measurement of $\mathrm{CO}$ concentration in the air [129,142]. Sensors, such as MQ-7 [143] or MQ-9 [144], are used for these measurements.

MS. Rane et al. created a wireless sensor network to measure AQI in real-time [145]. They focused on the cheap, affordable sensors mentioned above. The result of the work was the calculation of AQI in the main node using smaller wireless AQI sensors. Alternatively, K.M. Ng et al. introduced remote monitoring of AQI using MyRio-LabVIEW [146]. They presented a project where they wirelessly measured the value of $\mathrm{CO}$ concentration using the MQ-7 sensor and subsequently processed the obtained data using a platform from LabVIEW.

In the field of IoT, R. Firdaus et al. created an air quality monitoring system using LPWAN LoRa [147]. They created a system that uses IoT technology to monitor temperature, pressure, humidity, and the concentration of $\mathrm{CO}$ and $\mathrm{CO}_{2}$. The aforementioned MQ-7 sensor was used to measure the $\mathrm{CO}$ concentration. The measured data are stored in a cloud, from where they can be viewed using the Android system. Similarly, R.K. Kodali used IoT technology to measure air quality using the MQTT protocol [148]. The paper focuses on measuring dust and $\mathrm{CO}$ in smoke produced by factories in India. These factories are the primary contributors to air pollution as solid particles cause human health problems, such as asthma and other respiratory diseases. In the work, the author obtains values from sensors and, later on, sends them to the cloud. This measured data is displayed on the website and the mobile application. Another application of CO measurement in IoT can be found in References [149-151].

An interesting application of $\mathrm{CO}$ measurement is proposed for mining tunnels. M.M. Tao developed an alarm system based on Single-chip, which measures the concentration of ammonia and CO in tunnels [152]. When the limit values are exceeded, an alarm is triggered, and a buzzer makes noise.

S. Kouda et al. proposed modeling of the MQ-9 gas sensor, where the modeling is based on artificial neural networks (ANN) [153]. The sensor works in a dynamic environment and expresses the behavior model of the MQ-9 sensor. Accordingly, it takes into account non-linearity and sensitivity in gas, temperature, and humidity selectivity.

\subsubsection{Comparison of Gas Sensors}

The following, Table 5, summarizes all used sensors, together with their basic properties. 
Table 5. Review of gas sensors with main properties.

\begin{tabular}{|c|c|c|c|c|}
\hline Gas & Label & $\begin{array}{l}\text { Detection Range } \\
\text { [ppm] }\end{array}$ & $\begin{array}{c}\text { Power } \\
\text { Consumption } \\
{[\mathrm{mW}]}\end{array}$ & Use \\
\hline \multirow{3}{*}{$\mathrm{CO}_{2}$} & MQ-135 & 10-1000 & $\leq 950$ & $\begin{array}{c}\text { References } \\
{[127,128,130,131,} \\
134,135]\end{array}$ \\
\hline & MG811 & $350-10,000$ & $850 \pm 120$ & $\begin{array}{c}\text { References } \\
{[132,133,139-141]}\end{array}$ \\
\hline & CCS811 & $400-32,768$ & 60 & $\begin{array}{c}\text { References } \\
\text { [136-138] }\end{array}$ \\
\hline \multirow[t]{2}{*}{$\mathrm{CO}$} & MQ-7 & $20-2000$ & 350 & $\begin{array}{c}\text { References } \\
{[129,130,143,145,} \\
147,152]\end{array}$ \\
\hline & MQ-9 & 10-1000 & $\leq 350$ & $\begin{array}{c}\text { References } \\
{[142,144,153]}\end{array}$ \\
\hline
\end{tabular}

\subsection{Temperature Sensors (Smallest and Accurate)}

Thermocouple probes are standard equipment for recording forest fire data for later analysis. Despite advances in technology, these commercially available probes are still expensive; thus, it is sometimes not possible to cover a large area with them. As these probes are used in a high-temperature environment, it is not possible to use any cheap temperature sensor. Currently, there are several projects $[154,155]$ influencing the development of thermocouple probes for these purposes and available at reduced cost compared to commercial technologies. These papers are dealing with a K-type thermocouple.

There are thermocouples also used in coffee roasters [156]. The process of roasting coffee has a significant effect on the taste of a coffee drink. The roasting has several levels, and it is necessary to ensure the exact temperature in each individual process. Thermocouples are used at the entrance to measure quite high-temperatures in this area. A similar project [157] deals with a black pepper dryer, and a K-type thermocouple is used to measure the temperature. The quality of the pepper depends on a precise measurement.

In most cases, thermocouples are used in industrial applications to measure higher temperatures, such as to regulate the plate temperature [158]. Alternatively, an interesting example of thermocouple temperature measurement during lathe turning is proposed in Reference [159]. When cutting metals, the measurement of the temperature of the cutting tool is influenced by various factors. Because the lifespan of a cutting tool depends on the cutting temperature, it is important to predict the generation of heat in the tool by utilizing reliable techniques. A K-type thermocouple was used for this purpose.

There are a large number of other interesting papers where thermocouples are used [160-163].

In this paper, our aim is to determine the smallest possible temperature sensor with sufficient accuracy and relatively low cost.

\section{Comparison}

Table 6 describes the individual thermocouples $[164,165]$ and their properties. 
Table 6. Review of thermocouples with main properties.

\begin{tabular}{|c|c|c|c|c|}
\hline \multirow{2}{*}{$\begin{array}{l}\text { Thermo- } \\
\text { couple }\end{array}$} & \multicolumn{2}{|c|}{ Temperature Range $\left[{ }^{\circ} \mathrm{C}\right]$} & \multirow{2}{*}{ Error $[\%]$} & \multirow{2}{*}{ Use } \\
\hline & Short Measurement & Long Measurement & & \\
\hline Type E & 40-900 & $0-800$ & \pm 0.50 & $\begin{array}{l}\text { Stronger signal in low-temperature } \\
\text { range, more stable }\end{array}$ \\
\hline Type J & $-180-800$ & $0-750$ & \pm 0.75 & $\begin{array}{c}\text { Short lifespan in } \\
\text { high-temperature range }\end{array}$ \\
\hline Type K & $-180-1300$ & $0-1100$ & \pm 0.75 & $\begin{array}{l}\text { Cheap, precise, reliable, wide } \\
\text { temperature range }\end{array}$ \\
\hline Type N & $-270-1300$ & 0-1100 & \pm 0.75 & $\begin{array}{l}\text { Expensive, more accurate in } \\
\text { low-temperature range }\end{array}$ \\
\hline Type R & $-50-1700$ & $0-1600$ & \pm 0.25 & Expensive, high precision and stability \\
\hline Type S & $-50-1750$ & $0-1600$ & \pm 0.25 & Expensive, high precision and stability \\
\hline Type T & $-250-400$ & $-185-300$ & \pm 0.75 & $\begin{array}{l}\text { Extremely reliable in } \\
\text { low-temperature range }\end{array}$ \\
\hline Type B & $0-1820$ & $200-1700$ & \pm 0.50 & $\begin{array}{l}\text { Stable and precise in extremely } \\
\text { high-temperature range }\end{array}$ \\
\hline
\end{tabular}

\subsection{LiDAR (Smallest and Low-Cost)}

When trying to choose the smallest possible LiDAR, we also pay attention to sufficient accuracy and affordability.

In recent years, light detection and ranging technology (LiDAR) has been used in countless applications. Over the years, the design of the LiDAR system has significantly improved, leading to a design with remarkably low cost, size, weight, and higher performance requirements. These systems can collect spatial information and are available in three variants: one-dimensional (1D), two-dimensional (2D), and three-dimensional (3D).

Many application-specific papers on LiDAR technologies have been published in the past, such as in References [166-171].

The primary area for the LiDAR's application is autonomous vehicles. The detection of obstacles in autonomous vehicles is mandatory to maintain the safety of the driver and pedestrians and the navigation of the vehicle during the journey to the desired destination. Currently, in-vehicle warning systems are integrated to help the driver move safely on the road. However, autonomous vehicles must recognize the obstacles themselves and start moving safely around the detected objects. Several applications and suggestions have emerged that address the use of LiDAR for safe driving [172-176]. Based on the measured data from LiDAR, the algorithms generate an optimized route with adaptation to the current position of the vehicle, the location of obstacles, and the capabilities of the car. The route planning is updated in real-time, while new or moving obstacles are identified.

A similar use of LiDAR can be found in autonomous robots [177-181], which have the task of avoiding an obstacle or overcome a given obstacle to minimize damage to the robot. Like autonomous cars and robots, autonomous drones must detect an obstacle in real-time and avoid it. References [182,183] describe proposals for UAV (Unmanned Aerial Vehicles), which use LiDAR technology to detect obstacles.

Modern technologies can make life much easier for people with disabilities. An example is the design of a wheelchair for the disabled or the elderly [184,185]. Reference [184] uses LiDAR technology to avoid collisions with static and moving obstacles. Two additional ultrasonic transducers were used in conjunction with LiDAR to ensure greater safety.

Reference [186] suggests the use of a small LiDAR as an early warning for bikers before an approaching vehicle comes from behind. LiDAR is the part of an evaluation unit that communicates with an intelligent helmet that alerts the driver of the motorcycle in time when the car is approaching to prevent a serious accident. Similarly, J.V. Brummelen and his team designed a similar technology, but for cyclists [187]. They placed a LiDAR on the back seat, along with two ultrasonic sensors. Depending on the approaching vehicle, the algorithm generates appropriate warning signals so that the cyclist can assess the risk of a collision based on the distance, speed, and direction of the approaching vehicle. 


\section{Mobile Robots for Special Applications}

Technological advancements in the past decade have given rise to the utilization of robotic technology in different fields: surveillance, reconnaissance, search, and rescue. For the purpose of minimizing the risks for rescuers, good practice speaks in favor of utilizing mobile robots in their teams. Examples of such an application are various, including: police robots, firefighter robots, and military.

\subsection{Search and Rescue Robots}

The main mission for the robots and their operators is to find victims, establish what their situation is, and then report back their findings based on a map of the building, tunnels, etc. These places of information will immediately be given to rescue teams preparing to save all victims being possibly found. Moreover, some other expectations from rescue robots pose: ability to autonomously find compromised and collapsed structures and provide shoring, find victims and ascertain their conditions, deliver sustenance, and communications to victims, and lastly, emplace sensors, such as acoustic, thermal, gas, etc.

The prime example of such a robot is a PackBot [188]. The PackBot is a multi-mission tactical mobile robot developed and manufactured by iRobot. Bearing in mind, it is designed to carry out dangerous missions. The robot carries out surveillance and reconnaissance, detection, building and route clearance, explosive ordinance disposal, and vehicle inspections. In line with this, it can be easily configured based on the operators' mission needs. The PackBot features a modular design, incorporating an array of various sensors [188].

The robot has a manipulator to inspect hazardous materials. More precisely, the front bay is mounted with a wide-angle drive camera. Besides, the machine is also fitted with a small arm manipulator featuring a color camera for conducting manipulation and inspection. Last of all, the PackBot was designed with a built in thermal camera, an explosives detection sensor, and a HazMat kit to detect chemical and biological materials.

Our attention deserves a simpler version of the aforementioned robot, as well [189]. Accordingly, the authors designed a crawler rescue robot with a robotic arm attached to it. The arm handles detonation of explosives, mines, and other objects. Besides, the robot also includes sensory equipment, where vital usage of low-cost sensors, e.g., gas sensors, thermistors, humidity sensors, etc., found its application. Authors used the ZigBee communication protocol for communication, and it was controlled by virtue of an Arduino and Raspberry Pi module.

\subsection{Fire Robots}

The most popular firefighting robots in the field today were designed by Howe \& Howe. The robots names are Thermite RS1-T3 and RS2-T2 [190]. Both are powered by diesel engines, controlled remotely, and can climb slopes up to 70 degrees [190]. They can blast out up to $9500 \mathrm{~L}$ of water and foam per minute, and, for this reason, the workhorses are intentionally designed to tackle major industrial fires, such as oil refinery blazes.

A robot named Colossus [191] saved the French Notre-Dame Cathedral. This robot resembles WALL-E and has a capacity of $2500 \mathrm{~L}$ of water per minute. Aside from extinguishing fire, the joystick-controlled Colossus can also haul firefighting equipment, as well, and transport wounded victims. This robot was designed by Shark Robotics company.

\subsection{Surveillance and Reconnaissance Robots}

The first interesting device for telemonitoring and surveillance is made up in a form of the Recon Scout robot [192]. It is a two-wheel mobile robot with a titanium body and wheels of urethane plastic. Forward movement facilitates the so-called tail being simultaneously the support of the robot. The robot can travel speed of $1.1 \mathrm{~km} / \mathrm{h}$. The range inside a building is $30 \mathrm{~m}$, and outside is $70 \mathrm{~m}$. The robot is equipped with a black and white camera.

The second robot being put forward is EyeDrive [193]. This is a four-wheeled robot produced in Israel. The system of cameras makes it feasible to obtain a panoramic view 
with an image definition of $2500 \times 570$ pixels. For the sake of sound transmission, the build in microphone enables hearing sound from a distance of $10 \mathrm{~m}$. The robot's range inside the building is $70 \mathrm{~m}$, whilst it is $300 \mathrm{~m}$ outside. The robot can bear additional loads, such as sensors, explosives, etc.

The mobile robot SpyBowl [194] must be thrown or rolled toward the target. The outer shell, with respect of its purpose, is made from an aluminum, covered by rubber, coating in the form of a ball. In terms of audiovisual perception, it is equipped with four cameras, allowing the acquisition of static images, and with microphones transmitting the sound. Furthermore, the SpyBowl can rotate about its vertical axis, which allows us to watch all environments dynamically. Additionally, the image can be seen from each camera independently. The range of the radio transmission varies between $20-30 \mathrm{~m}$ inside a building, and 100-300 m outside of it.

A similar robot, regarding design, is Eye Ball [195]. It is designed for throwing, rolling, or dropping. In terms of providing audio and video transmissions in real-time, the device is equipped with one camera, providing a good quality picture. To collect complete information about the environment, Eye Ball rotates about its own axis. Its extra software makes it feasible to acquire a panoramic view. Besides, the device has IR, and, thanks to it, the camera can see in darkness. Radio and video transmission effectively work up to a distance of up to $125 \mathrm{~m}$, depending on the surrounding environment.

\section{Design of the Reconnaissance Robot}

Given all the possibilities where SR can be used (Section 1), the writers of this paper identified a narrow area in which there is an effort to design their specific SR. This area covers rescues or reconnaissance applications. Thus, our idea is to design the SR that will serve as a reconnaissance SR with sensory equipment that makes it likely to provide a certain type of intervention (especially intervention in the road tunnel), so that the lives of firefighters would not be endangered during the intervention of the dangerous area.

The principle of direct driving method provides the basis for our SR (Figure 10). Let us turn to architecture of our robot in greater detail. Firstly, the internal control unit (ICU) controls and navigates the robot to the accident area, and, secondly, the sensors unit (SU), is made up of of a measuring head, where sensors collecting data about the specific environment, and the pull-out mechanism, which extends the measuring head out of the shell are placed. The SU will be protected from external influences by the shell of the SR. The advantage of this design will be that the SU is directly connected to the ICU. Thus, the measured data will not have to be transmitted by wireless technology between the two parts. This design is unique and specific and was ultimately designed specifically for this purpose. The SR features two modes. The first one is the rolling mode (Figure 11a), where the measuring head is OFF and inside of the shell. The second one is the measuring mode (Figure 11b), where the measuring head is ON and outside of shell.

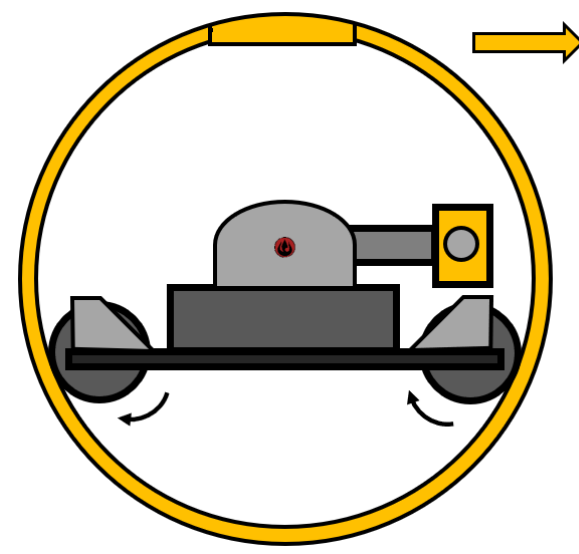

Figure 10. Principle sketch of our SR. 


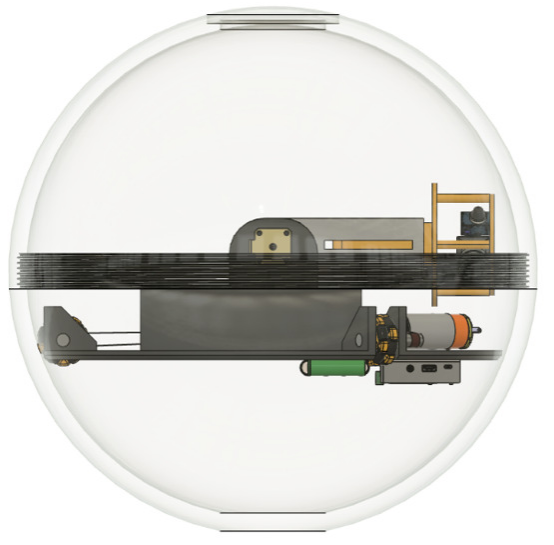

(a)

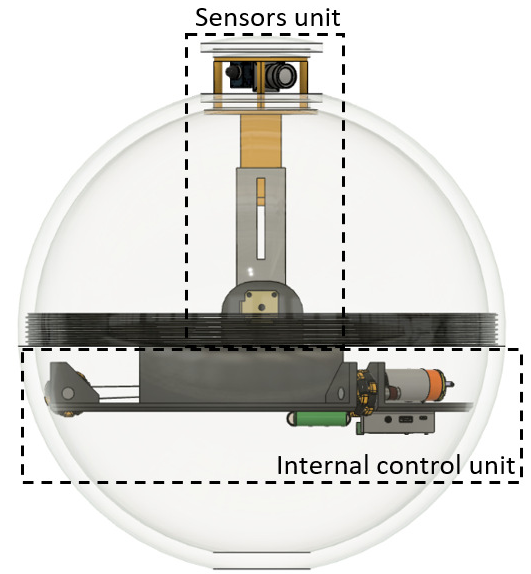

(b)

Figure 11. Modes of our SR. (a) Rolling mode. (b) Measuring mode.

\subsection{Internal Control Unit (ICU)}

The foundation of the SR is the ICU (Figure 12), consisting of the following parts: control unit (microcomputer), drive control module, DC motors, sensors, power supply module, and wireless communication module.

A microcomputer with sufficient computing power was chosen as the main control unit because the control algorithm must be executed in real-time. The unit mentioned will command the drive control module, the sensors determined for robot driving, and the communication module. With respect to many previous papers, we opted for the Raspberry $\mathrm{Pi} 4$ as the control unit.

The drive control module is determined to control 3 motors, driving the SR. Based on the motor's specification given below, a module with a maximum current of $10 \mathrm{~A}$ was defined. In terms of the application case presented, a module with the designation MDD10A was selected.

The motors are independent of each other, with a short timing belt of two motors that will connect the omnidirectional wheels, and a longer timing belt the third motor that will connect to the omnidirectional wheel, respectively. For the usage of the omnidirectional wheels, a diameter of $80 \mathrm{~mm}$ appeared to be most appropriate. The reason for such an architecture is coupling of all motors and ensuring that the CoM is moved closer to the shell of the SR. In this case, DC motors 36GP-555 ABHL with a voltage of $12 \mathrm{~V}$ were designed. The DC motor has a ratio of 5.2, which means 1150 RPM when the motor is unloaded. A nominal torque is $3 \mathrm{~kg} \cdot \mathrm{cm}$, at $880 \mathrm{RPM}$, with a rated current up to $2 \mathrm{~A}$. When maximally loaded, the maximum current take-off is $9.5 \mathrm{~A}$, based on which the drive control module was determined. An encoder is part of the motor, as well.

Sensors are required to determine the position of the ICU, movement, rotation, etc. The primary sensors of the SR taken into consideration are the accelerometer, the gyroscope, the sensors of the current flowing into the motors, and the speed sensor of the motor. These sensors will be, in most respects, used for the inertial navigation system of the robot because the SR will move in closed spaces, such as a tunnel, since it is not possible to monitor the robot's movement there using GPS.

The power supply module is used to provide enough power for all modules in ICU and SU. This module will consist of batteries with $12 \mathrm{~V}$ and a step-down converter of $12 \mathrm{~V}$ to $5 \mathrm{~V}$. In addition, a charging module will be connected to the batteries, which will be used to charge the batteries.

The last equipped module is a wireless communication module. This module will be used to receive control commands and to send measured data from each sensor and scanning device. Specifically, we can consider Bluetooth, WiFi, ZigBee, LoRa, and Thread, or using free communication bands, such as $868 \mathrm{MHz}$ or $443 \mathrm{MHz}$, for the sake of wireless 
communication. As the SR will move in a closed space, especially in tunnels, it is necessary to bear in mind several factors play a pivotal role in the signal transmission in closed spaces and, in turn, choose the most appropriate technology.

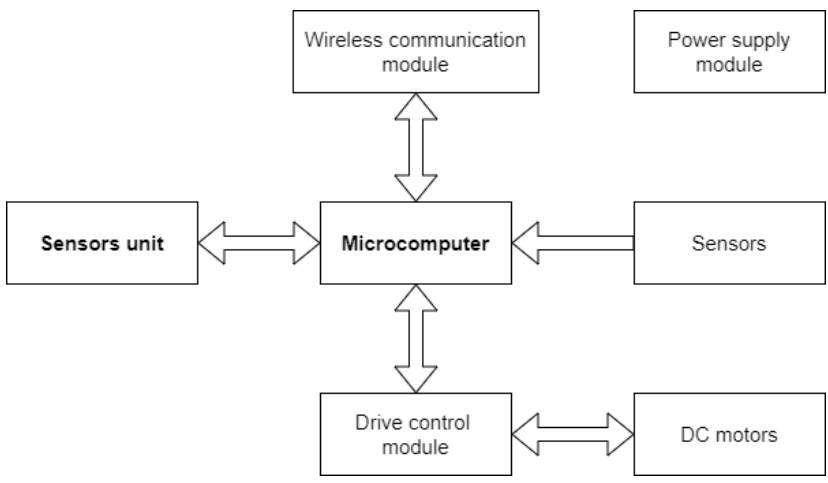

Figure 12. Simple diagram of an Internal Control Unit (ICU).

\subsection{Sensors Unit (SU)}

The SU (Figure 13) will be used for the measurement of dangerous gases and temperature in the vicinity of the SR, and the scanning device will be used for the mapping of the space in which the SR is located. This SU consists of: a microcomputer, scanning devices (LiDAR and camera), gas sensors, temperature sensors, and pull-out mechanism.

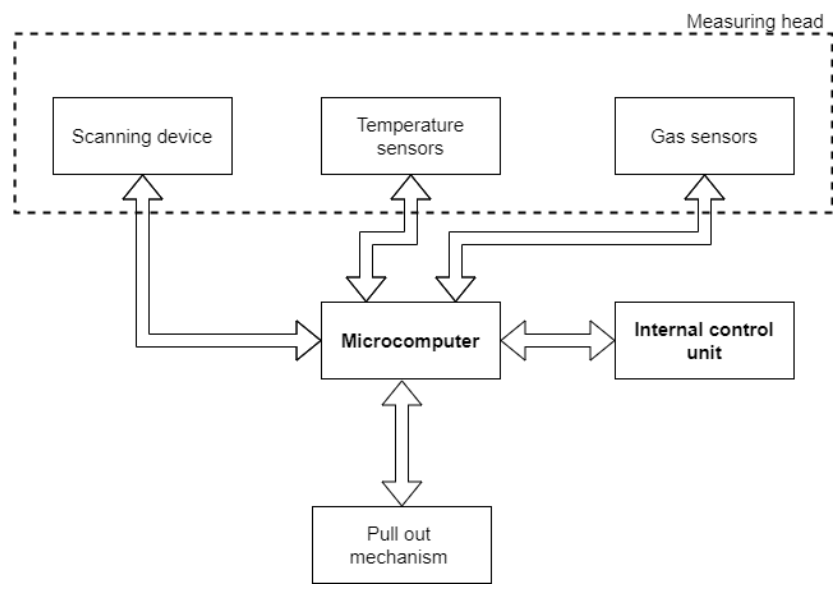

Figure 13. Simple diagram of Sensors Unit (SU).

\section{Discussion}

Currently, SRs are widely preferred in various fields of application, such as space exploration, monitoring, and surveillance of buildings and large areas. Despite the frequent usage of standard robots, various alternatives have also arisen, such as amphibians, hybrids in connection with a drone, or hybrids in connection with a walking robot. If we look at the histogram (Figure 14) below (based on the Web of Science), we can observe the largest expansion of SRs was from 2015 to 2019. Today, the trend with SRs is in decline (October 2021). 


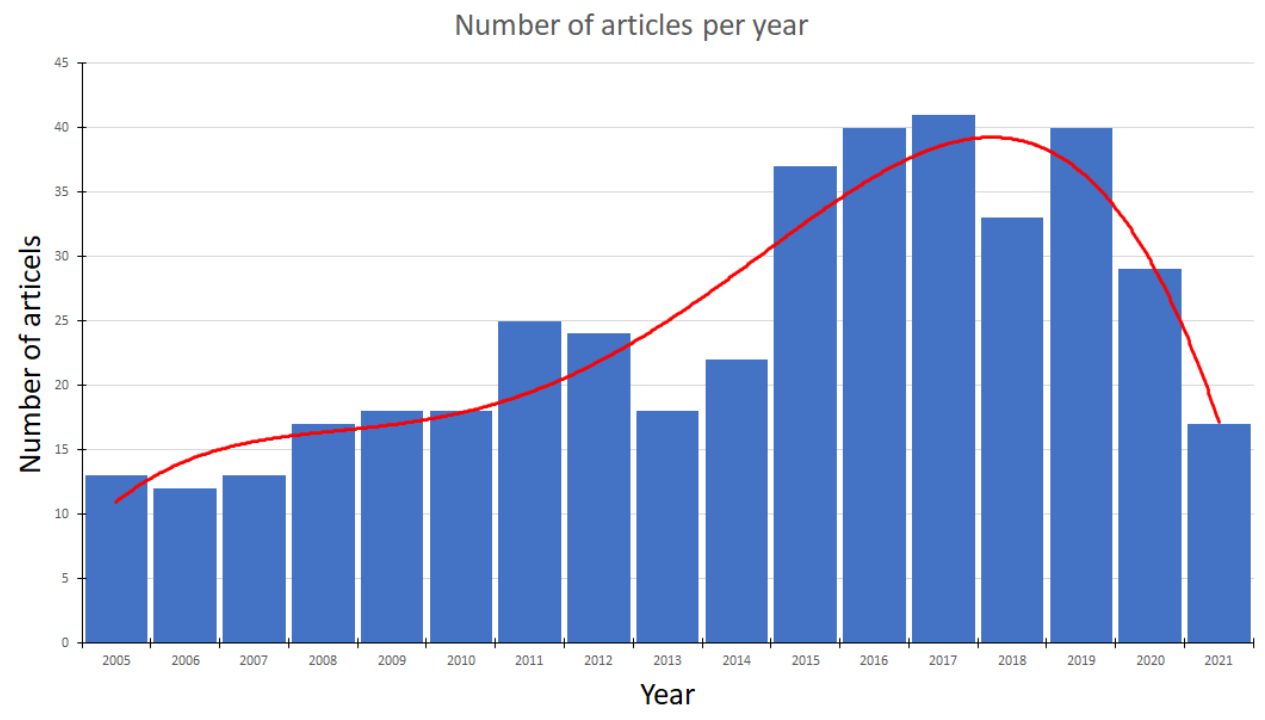

Figure 14. Histogram of articles about SR.

In Section 4, scholars focused on a review of articles, where sensors, such as cameras, gas sensors, thermocouples, or LiDARs, in low-cost applications, were used. In the current section, we focused on two types of cameras. First, on the account of the camera capturing the visible spectrum, we described 4 simple and low-cost cameras. We primarily identified their resolution, maximum image rate, and power consumption. The rationale for the second type of camera was its working within the IR spectrum, which turns into a description of 2 types of these cameras. We put emphasis on the same properties, such as cameras working in the visible spectrum. Histogram 2 shows the number of publications on these low-cost cameras per year. It is obvious (from histogram 2) that the trend in the use of these low-cost cameras is growing up every year. Later on, we focused on gas sensors. In general, $\mathrm{CO}$ and $\mathrm{CO}_{2}$ are the most dangerous gases for humans, so we described low-cost sensors that can measure these two types of gases. Accordingly, we focused on detection range and power consumption. Therefore, a description of the 3 most common $\mathrm{CO}_{2}$ sensors, as well as 2 types of $\mathrm{CO}$ sensors, was carried out in more detail. Figure 15 proves that the largest boom in gas detection was in the period 2017-2019. The following part of this section described thermocouples, and it included widely used thermocouple of type K. Figure 15 shows that the largest boom in thermocouples detection of temperature in low-cost design was in the period 2016-2020. The last part of this section attended low-cost LiDAR scanning. This review shows the possibility for a sensor's usage in creating 2D map of the place. Figure 15 shows that low-cost LiDAR technology can be used very often in a simple design.

Section 5 provides insights into the various mobile robots for special applications. We focus on surveillance, reconnaissance, fire, search, and rescue robots. Many fire, search, and rescue robots use belts, and the construction is massive. On the contrary, surveillance and reconnaissance mobile robots are simple and small. These are usually four-wheeled (two-wheeled) robots or robotic balls that have environmental sensors. The perspectives in Section 5 determine, in a variety of ways, the focus of our paper.

In Section 6, we propose a new design of the SR for special applications. This SR will serve as a reconnaissance robot for rescue services to survey the road tunnel during a traffic accident. More precisely, it is an SR with a direct-driving mechanism, which also involves a measuring unit that slides out of the robot shell. The sensor head, being mounted on the pull-out mechanism, is used to obtain data about the environment. 


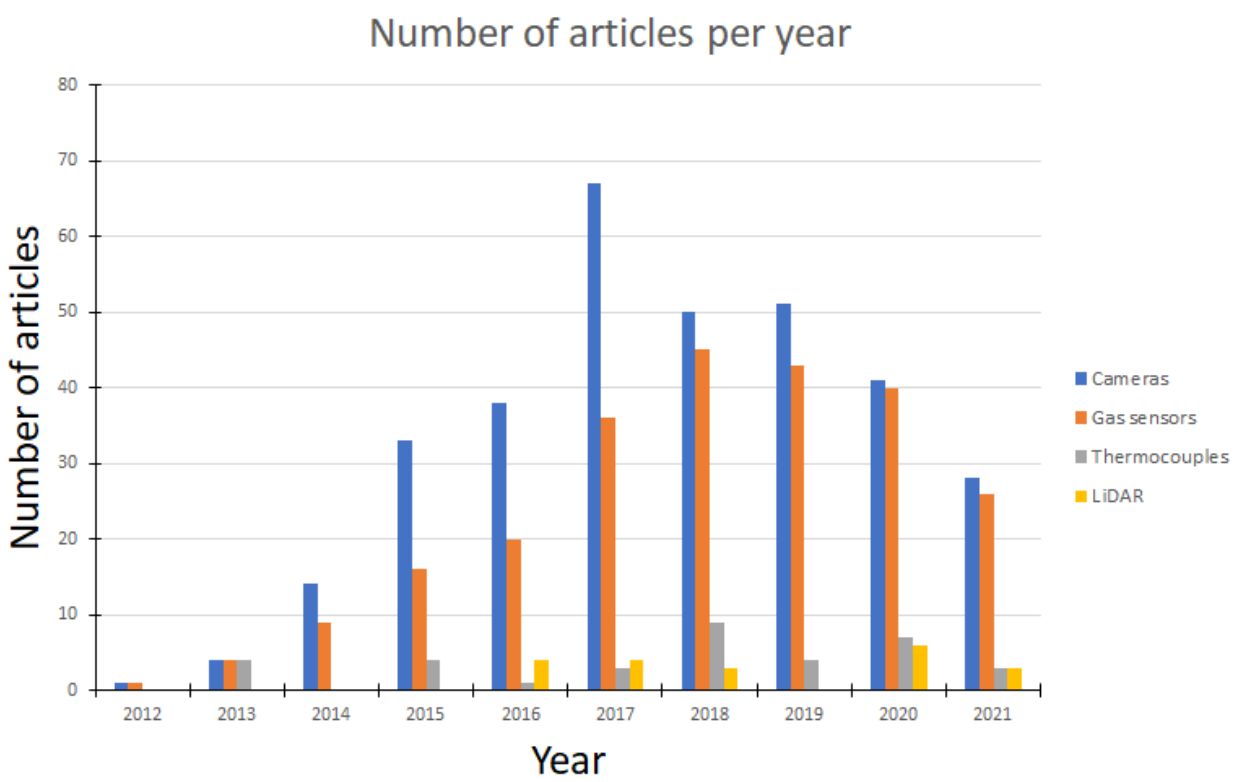

Figure 15. Histogram of articles about cameras, gas sensors, thermocouples, and LiDARs.

\section{Conclusions}

In most cases, mobile robots for special applications are either usually robust or small but without direct control. Our proposed mobile robot eliminates these disadvantages in that it combines these two categories of robots into one spherical robot.

Consequently, our proposed mobile robot will be used for reconnaissance in tunnels during an emergency. Secondly, writers achieved holonomy in terms of using the direct driving mechanism. Besides that, another advantage of using driving mechanism mentioned arises. To put it clearly, it is the direct connection of the internal control unit to the sensor unit.

Next, the Raspberry Pi 4 was designed as the main control unit. DC motors with $1150 \mathrm{RPM}$ and $12 \mathrm{~V}$ voltage, as well as omnidirectional wheels with a diameter of 80 , appeared appropriate for movement of the robot. Last but not least, motors are controlled by an MDD10A controller.

An overview of sensors suitable for our sensor unit has been created. The solutions we propose are as follows. A preference for a $\mathrm{CO}_{2}$ sensor was given to the MQ- 135 sensor. The MQ-7 sensor will execute measurement of $\mathrm{CO}$. Furthermore, K-type thermocouples will be used for temperature sensing. The selection of OV7670 and MLX90640 type cameras was made from the available papers. Finally, LiDAR RPLIDAR-A1 can be used as a scanning device for our robot.

As the robot is currently in the construction and design stage, it is not yet possible to publish the results of the corner measurements. The results will be then summed up in a following article.

Author Contributions: Conceptualization, M.B. and R.P.; methodology, M.B.; validation, K.R., A.J. and Z.Ł.; formal analysis, T.T., D.N. and M.B.; investigation, M.B.; resources, M.B., A.J., K.R. and R.P.; writing-original draft preparation, M.B. and P.K.; writing—review and editing, K.R., A.J., T.T. and Z.Ł.; visualization, M.B. and P.K.; supervision, A.J.; project administration, R.P.; funding acquisition, R.P. All authors have read and agreed to the published version of the manuscript.

Funding: The research was funded by the project APVV-17-0014 Smart tunnel: "Telematic support in case of emergencies in the road tunnel" and VEGA 1/0241/22 Mobile robotic systems for support during crisis situations.

Institutional Review Board Statement: Not applicable.

Informed Consent Statement: Not applicable. 
Data Availability Statement: Not applicable.

Conflicts of Interest: The authors declare no conflict of interest.

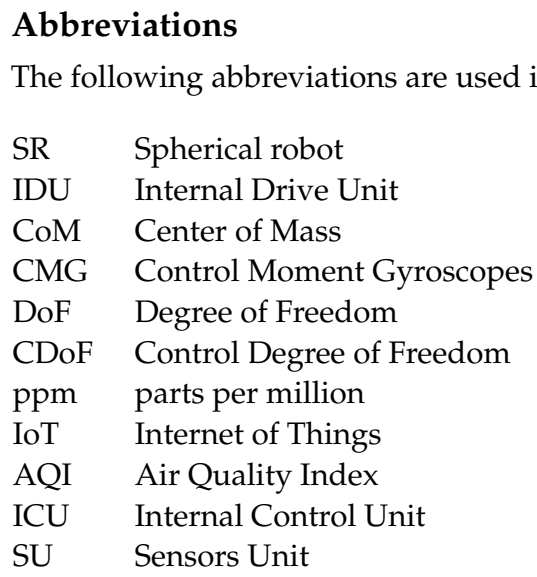

\section{References}

1. Bujňák, M.; Pirník, R.; Nemec, D.; Hruboš, M. Universal firefighter sensor for dangerous road tunnel environment. Transp. Res. Procedia 2021, 55, 1019-1025. [CrossRef]

2. Chase, R.; Pandya, A. A Review of Active Mechanical Driving Principles of Spherical Robots. Robotics 2012, 1, 3-23. [CrossRef]

3. Borrmann, D.; Nüchter, A.; Bredenbeck, A.; Zevering, J.; Arzberger, F.; Reyes Mantilla, C.A.; Rossi, A.P.; Maurelli, F.; Unnithan, V.; Dreger, H.; et al. Lunar Caves Exploration with the DAEDALUS Spherical Robot. In Proceedings of the 52nd Lunar and Planetary Science Conference 2021, Virtually, 15-19 March 2021. Available online: https:/ / www.hou.usra.edu/meetings/lpsc2021/pdf/20 73.pdf (accessed on 26 September 2021).

4. Southard, L.; Hoeg, T.M.; Palmer, D.W.; Antol, J.; Kolacinski, R.M.; Quinn, R.D. Exploring Mars Using a Group of Tumbleweed Rovers. In Proceedings of the 2007 IEEE International Conference on Robotics and Automation, Rome, Italy, 10-14 April 2007; pp. 775-780. [CrossRef]

5. $\quad$ Liang, G.; Luo, H.; Li, M.; Qian, H.; Lam, T.L. FreeBOT: A Freeform Modular Self-reconfigurable Robot with Arbitrary Connection Point-Design and Implementation. In Proceedings of the 2020 IEEE/RSJ International Conference on Intelligent Robots and Systems (IROS), Las Vegas, NV, USA, 24 October-24 January 2020; pp. 6506-6513. [CrossRef]

6. Abad, A.C.; Sarmiento, A.P.M.; Danseco, J.A.P.; Leon, J.S.D.; Otani, J.P.; Aguilar, P.S.B. Spherical Mobile Robots as Wireless Sensor Nodes for Ambient Temperature and Relative Humidity Monitoring. In Proceedings of the 2017 International Conference on Advanced Computing and Applications (ACOMP), Ho Chi Minh City, Vietnam, 29 November-1 December 2017 ; pp. 88-92. [CrossRef]

7. Zhang, M.; Chai, B.; Cheng, L.; Sun, Z.; Yao, G.; Zhou, L. Multi-Movement Spherical Robot Design and Implementation. In Proceedings of the 2018 IEEE International Conference on Mechatronics and Automation (ICMA), Changchun, China, 5-8 August 2018; pp. 1464-1468. [CrossRef]

8. Yao, Y.; Deng, Z.; Zhang, X.; Lv, C. Design and Implementation of a Quadrotor-Based Spherical Robot. In Proceedings of the 2021 IEEE 5th Advanced Information Technology, Electronic and Automation Control Conference (IAEAC), Chongqing, China, 12-14 March 2021; pp. 2430-2434. [CrossRef]

9. Dudley, C.J.; Woods, A.C.; Leang, K.K. A micro spherical rolling and flying robot. In Proceedings of the 2015 IEEE/RSJ International Conference on Intelligent Robots and Systems (IROS), Hamburg, Germany, 28 September-2 October 2015; pp. 5863-5869. [CrossRef]

10. Lu, P.; Xu, K.; Ding, X.; Jiang, S.; Tang, Z.; Wang, Y. Design and Analysis of a Flying-crawling Spherical Robot for Multi-mode Movement. In Proceedings of the 2019 IEEE International Conference on Robotics and Biomimetics (ROBIO), Dali, China, 6-8 December 2019; pp. 2855-2860. [CrossRef]

11. Geng, L.; Lin, Y.; Hu, Z.; Wang, C.; Meng, L.; Li, D. A new concept spherical underwater robot propelled by thrust vector synthetic jet actuator. In Proceedings of the OCEANS 2016, Shanghai, China, 10-13 April 2016; pp. 1-4. [CrossRef]

12. Bi, L.; Guo, J.; Guo, S.; Zhong, Z. Kinematic analysis on land of an amphibious spherical robot system. In Proceedings of the 2015 IEEE International Conference on Mechatronics and Automation (ICMA), Beijing, China, 2-5 August 2015; pp. $2082-2087$. [CrossRef]

13. Xing, H.; Guo, S.; Shi, L.; Hou, X.; Liu, Y.; Liu, H.; Hu, Y.; Xia, D.; Li, Z. A Novel Small-scale Turtle-inspired Amphibious Spherical Robot. In Proceedings of the 2019 IEEE/RSJ International Conference on Intelligent Robots and Systems (IROS), Macau, China, 3-8 November 2019; pp. 1702-1707. [CrossRef]

14. Prasad, B.; Agrawal, A.; Viswanathan, V.; Chowdhury, A.R.; Kumar, R.; Panda, S.K. A visually guided spherical underwater robot. In Proceedings of the 2015 IEEE Underwater Technology (UT), Chennai, India, 23-25 February 2015; pp. 1-6. [CrossRef] 
15. Singh, A.; Paigwar, A.; Manchukanti, S.T.; Saroya, M.; Chiddarwar, S. Design and motion analysis of Compliant Omnidirectional Spherical Modular Snake Robot (COSMOS). In Proceedings of the 2018 International Conference on Reconfigurable Mechanisms and Robots (ReMAR), Delft, The Netherlands, 20-22 June 2018; pp. 1-10. [CrossRef]

16. Kim, D.; Kim, J.; Kim, D. Development of an omni-directional mobile base utilizing spherical robots as wheels. In Proceedings of the 2017 14th International Conference on Ubiquitous Robots and Ambient Intelligence (URAI), Jeju, Korea, 28 June-1 July 2017; pp. 370-371. [CrossRef]

17. Seeman, M.; Broxvall, M.; Saffiotti, A.; Wide, P. An Autonomous Spherical Robot for Security Tasks. In Proceedings of the 2006 IEEE International Conference on Computational Intelligence for Homeland Security and Personal Safety, Alexandria, VA, USA, 16-17 October 2006; pp. 51-55. [CrossRef]

18. Jose, J.A.C.; Basco, J.V.; Jolo, J.K.; Yambao, P.K.; Cabatuan, M.K.; Bandala, A.A.; Ching, P.M.L.; Dadios, E.P. Spherical Mobile Robot for Monitoring and Tracking Children Indoors. In Proceedings of the 2019 4th Asia-Pacific Conference on Intelligent Robot Systems (ACIRS), Nagoya, Japan, 13-15 July 2019; pp. 159-163. [CrossRef]

19. Ping, Y.; Hanxu, S.; Zhongiiang, Q.; Jiazhen, C. Design and motion control of a spherical robot with stereovision. In Proceedings of the 2016 IEEE 11th Conference on Industrial Electronics and Applications (ICIEA), Hefei, China, 5-7 June 2016; pp. 1276-1282. [CrossRef]

20. Potapov, E.V.; Ipatov, A.A.; Priorov, A.L.; Romanov, A.A. Developing Spherical Mobile Devices for Indoor Exploration. In Proceedings of the 2020 Systems of Signal Synchronization, Generating and Processing in Telecommunications (SYNCHROINFO), Svetlogorsk, Russia, 1-3 July 2020; pp. 1-4. [CrossRef]

21. Lin, K.; Liao, Y.; Guan, Y.; Yang, Y. Design and control of a miniature rolling robot for entertainment. In Proceedings of the 2016 IEEE International Conference on Robotics and Biomimetics (ROBIO), Qingdao, China, 3-7 December 2016; pp. 1826-1831. [CrossRef]

22. Xie, S.; Chen, J.; Luo, J.; Li, H.; Yao, J.; Gu, J. Dynamic analysis and control system of spherical robot for polar region scientific research. In Proceedings of the 2013 IEEE International Conference on Robotics and Biomimetics (ROBIO), Shenzhen, China, 12-14 December 2013; pp. 2540-2545. [CrossRef]

23. Culebro, J.; Aguirre, J.L.; Muñoz, S. Lagrangian model, simulation and control of a spherical robot. In Proceedings of the 2013 10th International Conference on Electrical Engineering, Computing Science and Automatic Control (CCE), Mexico City, Mexico, 30 September-4 October 2013; pp. 1-6. [CrossRef]

24. Niu, X.; Suherlan, A.P.; Soh, G.S.; Foong, S.; Wood, K.; Otto, K. Mechanical development and control of a miniature nonholonomic spherical rolling robot. In Proceedings of the 2014 13th International Conference on Control Automation Robotics \& Vision (ICARCV), Singapore, 10-12 December 2014; pp. 1923-1928. [CrossRef]

25. Mamaev, I.S.; Vetchanin, E.V. Dynamics of a spherical robot with periodically changing moments of inertia. In Proceedings of the 2020 International Conference Nonlinearity, Information and Robotics (NIR), Innopolis, Russia, 3-6 December 2020; pp. 1-5. [CrossRef]

26. Urakubo, T.; Monno, M.; Maekawa, S.; Tamaki, H. Dynamic Modeling and Controller Design for a Spherical Rolling Robot Equipped With a Gyro. IEEE Trans. Control. Syst. Technol. 2016, 24, 1669-1679. [CrossRef]

27. Armour, R.H.; Vincent, J.F.V. Rolling in nature and robotics: A review. J. Bionic Eng. 2006, 3, 195-208. [CrossRef]

28. Nemec, D.; Janota, A.; Hruboš, M. Šimák, V. Intelligent Real-Time MEMS Sensor Fusion and Calibration. IEEE Sens. J. 2016, 16, 7150-7160. [CrossRef]

29. Halme, A.; Schonberg, T.; Wang, Y. Motion control of a spherical mobile robot. In Proceedings of the 4th IEEE International Workshop on Advanced Motion Control-AMC'96-MIE, Mie, Japan, 18-21 March 1996; Volume 1, pp. 259-264. [CrossRef]

30. Mizumura, Y.; Ishibashi, K.; Yamada, S.; Takanishi, A.; Ishii, H. Mechanical design of a jumping and rolling spherical robot for children with developmental disorders. In Proceedings of the 2017 IEEE International Conference on Robotics and Biomimetics (ROBIO), Macau, Macao, 5-8 December 2017; pp. 1062-1067. [CrossRef]

31. Zhan, Q.; Cai, Y.; Yan, C. Design, Analysis and Experiments of an Omni-Directional Spherical Robot. In Proceedings of the 2011 IEEE International Conference on Robotics and Automation (ICRA), Shanghai, China, 9-13 May 2011 2011; pp. 4921-4926. [CrossRef]

32. Bicchi, A.; Balluchi, A.; Prattichizzo, D.; Gorelli, A. Introducing the "SPHERICLE": An experimental testbed for research and teaching in nonholonomy. In Proceedings of the International Conference on Robotics and Automation, Albuquerque, NM, USA, 25-25 April 1997; Volume 3, pp. 2620-2625. [CrossRef]

33. Ghariblu, H.; Mohammadi, H. Structure and dynamic modelling of a spherical robot. In Proceedings of the 2012 th International Symposium on Mechatronics and its Applications, Sharjah, United Arab Emirates, 10-12 April 2012; pp. 1-5. [CrossRef]

34. Alves, J.; Dias, J. Design and control of a spherical mobile robot. J. Syst. Control Eng. 2003, 217, 457-467. 095965180321700602. [CrossRef]

35. Chen, W.-H.; Chen, C.-P.; Tsai, J.-S.; Yang, J.; Lin, P.-C. Design and implementation of a ball-driven omnidirectional spherical robot. Mech. Mach. Theory 2013, 68, 35-48. [CrossRef]

36. Ivanov, A.P. On the control of a robot ball using two omniwheels. Regul. Chaot. Dyn. 2015, 20, 441-448. [CrossRef]

37. Chen, W.; Chen, C.; Yu, W.; Lin, C.; Lin, P. Design and implementation of an omnidirectional spherical robot Omnicron. In Proceedings of the 2012 IEEE/ASME International Conference on Advanced Intelligent Mechatronics (AIM), Kaohsiung, Taiwan, 11-14 July 2012; pp. 719-724. [CrossRef] 
38. Mukherjee, R.; Minor, M.A.; Pukrushpan, J.T. Simple motion planning strategies for spherobot: A spherical mobile robot. In Proceedings of the Proceedings of the 38th IEEE Conference on Decision and Control (Cat. No.99CH36304), Phoenix, AZ, USA, 7-10 December 1999; Volume 3, pp. 2132-2137. [CrossRef]

39. Javadi, A.H.; Mojabi, P. Introducing August: A novel strategy for an omnidirectional spherical rolling robot. In Proceedings of the 2002 IEEE International Conference on Robotics and Automation (Cat. No.02CH37292), Washington, DC, USA, 11-15 May 2002; Volume 4, pp. 3527-3533. [CrossRef]

40. Javadi, A.H.; Mojabi, P. Mojabi Introducing Glory: A novel strategy for an omnidirectional spherical rolling robot. J. Dyn. Syst. Meas. Control 2004, 126, 678. [CrossRef]

41. Zheng, Y.; Sun, H.; Jia, Q.; Shi, C.; Zhao, K. An omni-directional rolling spherical robot with telescopic manipulator. In Proceedings of the 2008 2nd International Symposium on Systems and Control in Aerospace and Astronautics, Shenzhen, China, 10-12 December 2008; pp. 1-6. [CrossRef]

42. Improve Your IAQ and Monitor $\mathrm{CO}_{2}$ (online), Onset Computer Corporation, March 2019; p. 14. Available online: www onsetcomp.com/blog/improve-your-iaq-and-monitor-co2/ (accessed on 29 September 2021).

43. Zadeh, F.K.; Moallem, P.; Asiri, S.; Zadeh, M.M. LQR motion control and analysis of a prototype spherical robot. In Proceedings of the 2014 Second RSI/ISM International Conference on Robotics and Mechatronics (ICRoM), Tehran, Iran, 15-17 October 2014; pp. 890-895. [CrossRef]

44. Muraleedharan, N.; Cohen, D.S.; Isenberg, D.R. Omnidirectional locomotion control of a pendulum driven spherical robot. In Proceedings of the SoutheastCon 2016, Norfolk, VA, USA, 30 March-3 April 2016; pp. 1-6. [CrossRef]

45. Li, W.; Zhan, Q. Kinematics-based four-state trajectory tracking control of a spherical mobile robot driven by a 2-DOF pendulum Chin. J. Aeronaut. 2019, 32, 1530-1540. [CrossRef]

46. Gajbhiye, S.; Banavar, R.N. Geometric modeling and local controllability of a spherical mobile robot actuated by an internal pendulum. Int. J. Robust Nonlinear Control 2016, 26, 2436-2454. [CrossRef]

47. Landa, K.; Pilat, A.K. Design and start-up of spherical robot with internal pendulum. In Proceedings of the 201510 th International Workshop on Robot Motion and Control (Romoco), Poznan, Poland, 6-8 July 2015; pp. 27-32. [CrossRef]

48. Michaud, F.; Caron, S. Roball, the Rolling Robot. Auton. Robot. 2002, 12, 211-222. [CrossRef]

49. Zhao, B.; Wang, P.; Hu, H.; Li, M.; Sun, L. Study on turning in place of a spherical robot based on stick-slip principle. In Proceedings of the 2009 IEEE International Conference on Robotics and Biomimetics (ROBIO), Guilin, China, 19-23 December 2009; pp. 771-775. [CrossRef]

50. Zhao, B.; Li, M.; Yu, H.; Hu, H.; Sun, L. Dynamics and motion control of a two pendulums driven spherical robot. In Proceedings of the 2010 IEEE/RSJ International Conference on Intelligent Robots and Systems, Taipei, Taiwan, 18-22 October 2010; pp. 147-153. [CrossRef]

51. Ghanbari, A.; Mahboubi, S.; Fakhrabadi, M.M.S. Design, dynamic modeling and simulation of a spherical mobile robot with a novel motion mechanism. In Proceedings of 2010 IEEE/ASME International Conference on Mechatronic and Embedded Systems and Applications, Qingdao, China, 15-17 July 2010; pp. 434-439. [CrossRef]

52. Yoon, J.; Ahn, S.; Lee, Y. Spherical robot with new type of two-pendulum driving mechanism. In Proceedings of the 2011 15th IEEE International Conference on Intelligent Engineering Systems, Poprad, Slovakia, 23-25 June 2011; pp. 275-279. [CrossRef]

53. Chen, M.; Sun, W.; Gao, Y.; Zhan, S.; Zhang, G.; Li, W.J. Development of a holonomic mobile spherical robot with 3D center of gravity shifting actuators. In Proceedings of the 2016 IEEE International Conference on Robotics and Biomimetics (ROBIO), Qingdao, China, 3-7 December 2016; pp. 438-442. [CrossRef]

54. Asiri, S.; Khademianzadeh, F.; Monadjemi, A.; Moallem, P. The Design and Development of a Dynamic Model of a Low-Power Consumption, Two-Pendulum Spherical Robot. IEEE/ASME Trans. Mechatron. 2019, 24, 2406-2415. [CrossRef]

55. Ahn, S.-S.; Lee, Y.-J. Novel Spherical Robot with Hybrid Pendulum Driving Mechanism. Adv. Mech. Eng. 2014, 6. [CrossRef]

56. DeJong, B.P.; Karadogan, E.; Yelamarthi, K.; Hasbany, J. Design and Analysis of a Four-Pendulum Omnidirectional Spherical Robot. J. Intell. Robot. Syst. 2016, 86, 3-15. [CrossRef]

57. Bastola, S.; Zargarzadeh, H. Super Twisting Sliding Mode Control of Spherical Robot. In Proceedings of the 2019 IEEE International Symposium on Measurement and Control in Robotics (ISMCR), Houston, TX, USA, 19-21 September 2019; pp. B2-1-1-B2-1-9. [CrossRef]

58. Kabala, M.; Wnuk, M. Design and construction of RoBall, a spherical, nonholonomic mobile robot. Wrocław 2004. INSTITUTE of CYBERNETYKI TECHNICZNE, WROCŁAW UNIVERSITY of TECHNOLOGY, PRE Series Report No. 48/2004. Available online: https: / / citeseerx.ist.psu.edu/viewdoc/download?doi=10.1.1.559.252\&rep=rep1\&type=pdf (accessed on 2 October 2021).

59. Ming, Y.; Zongquan, D.; Xinyi, Y.; Weizhen, Y. Introducing HIT Spherical Robot: Dynamic Modeling and Analysis Based on Decoupled Subsystem. In Proceedings of the 2006 IEEE International Conference on Robotics and Biomimetics, Kunming, China, 17-20 December 2006; pp. 181-186. [CrossRef]

60. Oumer, N.; Ylikorpi, T. A B Development of Wireless Control System for a Spherical Robot. Master's Thesis, Helsinki University of Technology, Department of Automation and Systems Technology, Helsinki, Finland, 2021. Available online: https://aaltodoc aalto.fi/bitstream/handle/123456789/3054/urn100005.pdf?sequence=1 (accessed on 5 October 2021).

61. Liu, D.; Sun, H.; Jia, Q. A family of spherical mobile robot: Driving ahead motion control by feedback linearization. In Proceedings of the 2008 2nd International Symposium on Systems and Control in Aerospace and Astronautics, Shenzhen, China, 10-12 December 2008; pp. 1-6. [CrossRef] 
62. Liu, D.; Sun, H.; Jia, Q.; Wang, L. Motion control of a spherical mobile robot by feedback linearization. In Proceedings of the 2008 7th World Congress on Intelligent Control and Automation, Chongqing, China, 25-27 June 2008; pp. 965-970. [CrossRef]

63. Liu, D.; Sun, H. Nonlinear sliding-mode control for motion of a spherical robot. In Proceedings of the 29th Chinese Control Conference, Beijing, China, 29-31 July 2010; pp. 3244-3249.

64. Wang, C.; Mayer, N.M.; Lin, R.; Lu, L. Mechanical and system design of Egg shape robot. In Proceedings of the 2017 International Automatic Control Conference (CACS), Pingtung, Taiwan, 12-15 November 2017; pp. 1-5. [CrossRef]

65. Kim, H.W.; Jung, S. Design and Control of a Sphere Robot Actuated by a Control Moment Gyroscope. In Proceedings of the 2019 19th International Conference on Control, Automation and Systems (ICCAS), Jeju, Korea, 15-18 October 2019; pp. 1287-1290. [CrossRef]

66. Urakubo, T.; Osawa, M.; Tamaki, H.; Tada, Y.; Maekawa, S. Development of a spherical rolling robot equipped with a gyro. In Proceedings of the 2012 IEEE International Conference on Mechatronics and Automation, Chengdu, China, 5-8 August 2012 pp. 1602-1607. [CrossRef]

67. Bhattacharya, S.; Agrawal, S.K. Spherical rolling robot: A design and motion planning studies. IEEE Trans. Robot. Autom. 2000, 16, 835-839. [CrossRef]

68. Tao, Y.; Hanxu, S.; Qingxuan, J. Variable Structure Control of Pendulum-driven Spherical Mobile Robots. In Proceedings of the 2010 3rd International Conference on Computer and Electrical Engineering (ICCEE 2010), Chengdu, China, 16-18 November 2010; IACSIT Press: Singapore, 2012; Volume 53. [CrossRef]

69. Joshi, V.; Banavar, R. Motion analysis of a spherical mobile robot. Robotica 2009, 27, 343-353. [CrossRef]

70. Joshi, V.; Banavar, R.; Hippalgaonkar, R. Design, Modeling and Controllability of a Spherical Mobile Robot. In Proceedings of the 13th National Conference on Mechanisms and Machines (NaCoMM07), Bangalore, India, 12-13 December 2007.

71. Shu, G.; Zhan, Q.; Cai, Y. Motion control of spherical robot based on conservation of angular momentum. In Proceedings of the 2009 International Conference on Mechatronics and Automation, Changchun, China, 9-12 August 2009; pp. 599-604. [CrossRef]

72. Qingxuan, J.; Yili, Z.; Hanxu, S.; Hongyu, C.; Hongyi, L. Motion control of a novel spherical robot equipped with a flywheel. In Proceedings of the 2009 International Conference on Information and Automation, Zhuhai/Macau, China, 22-24 June 2009; pp. 893-898. [CrossRef]

73. Chen, J.; Ye, P.; Sun, H.; Jia, Q. Design and motion control of a spherical robot with control moment gyroscope. In Proceedings of the 2016 3rd International Conference on Systems and Informatics (ICSAI), Shanghai, China, 19-21 November 2016; pp. 114-120. [CrossRef]

74. Artusi, M.; Potz, M.; Aristizabal, J.; Menon, C.; Cocuzza, S.; Debei, S. Electroactive Elastomeric Actuators for the Implementation of a Deformable Spherical Rover. IEEE/ASME Trans. Mechatron. 2011, 16, 50-57. [CrossRef]

75. Wait, K.W.; Jackson, P.J.; Smoot, L.S. Self locomotion of a spherical rolling robot using a novel deformable pneumatic method. In Proceedings of the 2010 IEEE International Conference on Robotics and Automation, Anchorage, AK, USA, 3-7 May 2010; pp. 3757-3762. [CrossRef]

76. Mahboubi, S.; Fakhrabadi, M.M.S.; Ghanbari, A. Design and Implementation of A Novel Hybrid Quadruped Spherical Mobile Robot. Robot. Auton. Syst. 2013, 61, 184-194. [CrossRef]

77. Aoki, T.; Ito, S.; Sei, Y. Development of quadruped walking robot with spherical shell-mechanical design for rotational locomotion In Proceedings of the 2015 IEEE/RSJ International Conference on Intelligent Robots and Systems (IROS), Hamburg, Germany, 28 September-2 October 2015; pp. 5706-5711. [CrossRef]

78. Huang, Z.; Jia, W.; Sun, Y.; Ma, S.; Wang, Z.; Pu, H.; Tian, Y. Design and analysis of a transformable spherical robot for multi-mode locomotion. In Proceedings of the 2017 IEEE International Conference on Mechatronics and Automation (ICMA), Takamatsu, Japan, 6-9 August 2017; pp. 1469-1473. [CrossRef]

79. Jia, W.; Huang, Z.; Sun, Y.; Pu, H.; Ma, S. Toward a novel deformable robot mechanism to transition between spherical rolling and quadruped walking. In Proceedings of the 2017 IEEE International Conference on Robotics and Biomimetics (ROBIO), Macau, Macao, 5-8 December 2017; pp. 1539-1544. [CrossRef]

80. Guo, S.; Cao, S.; Guo, J. Study on Collaborative Algorithm for a Spherical Multi-robot System based on Micro-blockchain. In Proceedings of the 2019 IEEE International Conference on Mechatronics and Automation (ICMA), Tianjin, China, 4-7 August 2019; pp. 1465-1470. [CrossRef]

81. Passaro, V.M.N.; Cuccovillo, A.; Vaiani, L.; Carlo, M.; Campanella, C.E. Gyroscope Technology and Applications: A Review in the Industrial Perspective. Sensors 2017, 17, 2284. [CrossRef]

82. aguchi, K.; Fukushima, K.; Ishitani, A.; Ikeda, M. Proposal of a semiconductor ring laser gyroscope. Opt. Quantum Electron. 1999, 31, 1219-1226. [CrossRef]

83. LeFevre Herve, C. The Fiber-Optic Gyroscope, 2nd ed.; Artech House: Boston, MA, USA; London, UK, 2014; ISBN 13: 978-1-60807-695-6.

84. Yang, Y.; Shen, T.; Guo, J. Fiber optic gyroscope technology and application. Infrared Laser Eng. 2007, 36, 626.

85. Acar, C.; Shkel, A. MEMS Vibratory Gyroscopes: Structural Approaches to Improve Robustness; Springer Science \& Business Media: Berlin/Heidelberg, Germany, 2008; ISBN 978-0-387-09535-6.

86. Nemec, D.; Šimák, V.; Janota, A.; Hruboš, M.; Bubeníková, E. Precise localization of the mobile wheeled robot using sensor fusion of odometry, visual artificial landmarks and inertial sensors. Robot. Auton. Syst. 2019, 112, 168-177. [CrossRef]

87. Roy, A.L.; Bhattacharyya, T.K. Design, fabrication and characterization of high performance SOI MEMS piezoresistive accelerometers. Microsyst. Technol. 2015, 21, 55-63. [CrossRef] 
88. Partridge, A.; Reynolds, J.K.; Chui, B.W.; Chow, E.M.; Fitzgerald, A.M.; Zhang, L.; Maluf, N.I.; Kenny, T.W. A high-performance planar piezoresistive accelerometer. J. Microelectromech. Syst. 2000, 9, 58-66. [CrossRef]

89. Han, Z.; Jiao, P.; Zhu, Z. Combination of Piezoelectric and Triboelectric Devices for Robotic Self-Powered Sensors. Micromachines 2021, 12, 813. [CrossRef]

90. Mukhiya, R.; Agarwal, P.; Badjatya, S.; Garg, M.; Gaikwad, P.; Sinha, S.; Singh, A.K.; Gopal, R. Design, modelling and system level simulations of DRIE-based MEMS differential capacitive accelerometer. Microsyst. Technol. 2019, 25, 3521-3532. [CrossRef]

91. Keshavarzi, M.; Yavand Hasani, J. Design and optimization of fully differential capacitive MEMS accelerometer based on surface micromachining. Microsyst. Technol. 2018, 25, 1369-1377. [CrossRef]

92. Choi, B.J.; Kim, B.; Jin, S.M.; Koo, J.C.; Chung, W.K.; Choi, H.R.; Moon, H. Magnetic landmark-based position correction technique for mobile robots with hall sensors. Intell. Serv. Robot. 2010, 3, 99-113. [CrossRef]

93. Sokolov, S.M.; Trifonov, O.V.; Yaroshevsky, V.S. Control system for spherical direct drive actuators with Hall sensors [mobile robots]. In Proceedings of the 1999 IEEE/SICE/RSJ, International Conference on Multisensor Fusion and Integration for Intelligent Systems, MFI'99 (Cat. No.99TH8480), Taipei, Taiwan, 18 August 1999; pp. 183-188. [CrossRef]

94. Ripka, P.; Arafat, M.M. Magnetic Sensors: Principles and Applications. In Reference Module in Materials Science and Materials Engineering; Elsevier Reference Collection: Amsterdam, The Netherlands, 2019. [CrossRef]

95. You, Z. Space Microsystems and Micro/nano Satellites, Chapter 9-Magnetometer Technology. In Space Microsystems and Micro/Nano Satellites; Butterworth-Heinemann: Oxford, UK, 2018; pp. 341-360. ISBN: 978-0-12-812672-1.

96. Ojeda, L.; Borenstein, J. Experimental results with the KVH C-100 fluxgate compass in mobile robots. In Proceedings of the IASTED International Conference on Robotics and Applications, Proceedings of the IASTED International Conference Robotics and Applications 2000, Honolulu, HI, USA, 14-16 August 2000.

97. Borenstein, J.; Everett, H.R.; Feng, L.; Wehe, D. Mobile robot positioning: Sensors and techniques. J. Robot. Syst.1997, 14, 231-249. [CrossRef]

98. Kraft, A.; Rupprecht, C.; Yam, Y.-C. Superconducting Quantum Interference Device (SQUID). UBC Phys. 2017. Available online: https://phas.ubc.ca/ berciu/TEACHING/PHYS502/PROJECTS/17SQUID.pdf (accessed on 3 February 2022).

99. Ripka, P. Magnetic Sensors and Magnetometers, 2nd ed.; Artech House: Boston, MA, USA; London, UK, 2021; ISBN 13: 978-1-63081-742-8.

100. Pedersen, L. Robotic deployment of electromagnetic sensors for meteorite search. In Proceedings of the 1998 IEEE International Conference on Robotics and Automation (Cat. No.98CH36146), Leuven, Belgium, 20 May 1998; Volume 1, pp. 618-623. [CrossRef]

101. Korepanov, V.; Pronenko, V. Induction magnetometers-design peculiarities. Sens. Transducers J. 2010, 120, 92-106.

102. Coillot, C.; Leroy, P.; Kuang, K. Induction magnetometers principle, modeling and ways of improvement. In Magnetic SensorsPrinciples and Applications; No. 1; InTech: Vienna, Austria, 2012; ISBN: 978-953-51-0232-8.

103. Sandoval, A.G.; Tíjaro, O.J.; Moreno, Y.T. Acquisition and storage of optical interference fringes by means of an embedded system. In Proceedings of the 2019 XXII Symposium on Image, Signal Processing and Artificial Vision (STSIVA), Bucaramanga, Colombia, 24-26 April 2019; pp. 1-5. [CrossRef]

104. Xiong, J.; Pan, Y.; Hou, Z.; Zhang, R. Research on the System of Image Acquisition and Wireless Transmission. Appl. Mech. Mater. 2014, 668, 1382-1385. [CrossRef]

105. Song, W.; Zhou, X.; Wan, X.; Li, X. Realization Of Vision Acquisition Module Based On STM32+OV7670 For Tunnel Robot. In Proceedings of the 2016 6th International Conference on Machinery, Materials, Environment, Biotechnology and Computer, Tianjin, China, 11-12 June 2016; Atlantis Press: Paris, France, 2016; pp. 1244-1247. [CrossRef]

106. Patel, D.; Parmar, R.; Desai, A.; Sheth, S. Gesture recognition using FPGA and OV7670 camera. In Proceedings of the 2017 International Conference on Inventive Systems and Control (ICISC), Coimbatore, India, 19-20 January 2017; pp. 1-4. [CrossRef]

107. Yao, J.; Yang, D. A Procedure of Image Acquisition and Display Based on Ov7670. In Proceedings of the 2015 International Conference on Applied Mechanics, Mechatronics and Intelligent Systems (AMMIS2015), Nanjing, China, 19-20 June 2015; pp. 381-384. [CrossRef]

108. Chen, M.; Mao, G.; Wang, Y. A Wireless Image Transmission System Based on Visible Light Communication. In Proceedings of the 2015 International Conference on Intelligent Systems Research and Mechatronics Engineering, Zhengzhou, China, 11-13 April 2015; Atlantis Press: Paris, France, 2015; Volume 121, pp. 827-830. [CrossRef]

109. Qi, W.; Wang, Y.; Li, C.; Zhang, D. Video monitoring system of security based on Wi-Fi. In Proceedings of the 2016 Chinese Control and Decision nce (CCDC), Yinchuan, China, 28-30 May 2016; pp. 2869-2874. [CrossRef]

110. Zhang, Y.; Xiao, G.; Xu, J. The Wireless Image Transmission System of Capsule Endoscope Based on STM32F103. In Proceedings of the 2016 2nd International Conference on Mechanical, Electronic and Information Technology Engineering (ICMITE 2016), Chongqing, China, 21-22 May 2016; pp. 297-303. [CrossRef]

111. Qin, L.; Hou, Z.; Wu, Y.; Tan, F.; He, F. A high-speed image acquisition and processing system in photoelectric tracking. In Proceedings of the SPIE 8194, International Symposium on Photoelectronic Detection and Imaging 2011: Advances in Imaging Detectors and Applications, 81942E, Beijing, China, 18 August 2011. [CrossRef]

112. Haro, M.S.; Bessia, F.A.; Pérez, M.; Blostein, J.J.; Balmaceda, D.F.; Berisso, M.G.; Lipovetzky, J. Soft X-rays spectroscopy with a commercial CMOS image sensor at room temperature. Radiat. Phys. Chem. 2020, 167, pp 108354. [CrossRef]

113. Géczy, A.; Melgar, R.D.J.; Bonyár, A.; Harsányi, G. Passenger detection in cars with small form-factor IR sensors (Grid-eye). In Proceedings of the 2020 IEEE 8th Electronics System-Integration Technology Conference (ESTC), Tonsberg, Norway, 15-18 September 2020; pp. 1-6. [CrossRef] 
114. Ionescu, V.M.; Enescu, F.M. Low cost thermal sensor array for wide area monitoring. In Proceedings of the 202012 th International Conference on Electronics, Computers and Artificial Intelligence (ECAI), Bucharest, Romania, 25-27 June 2020; pp. 1-4. [CrossRef]

115. Gochoo, M.; Tan, T.; Batjargal, T.; Seredin, O.; Huang, S. Device-Free Non-Privacy Invasive Indoor Human Posture Recognition Using Low-Resolution Infrared Sensor-Based Wireless Sensor Networks and DCNN. In Proceedings of the 2018 IEEE International Conference on Systems, Man, and Cybernetics (SMC), Miyazaki, Japan, 7-10 October 2018; pp. 2311-2316. [CrossRef]

116. Gu, N.; Yang, B.; Zhang, T. Dynamic Fuzzy Background Removal for Indoor Human Target Perception Based on Thermopile Array Sensor. IEEE Sens. J. 2020, 20, 67-76. [CrossRef]

117. Du, P.; She, L.; Wang, Y.; Chang, S.; Li, H. Design of intelligent air cooling radiator system based on TMS320C6748. In Proceedings of the 2020 39th Chinese Control Conference (CCC), Shenyang, China, 27-29 July 2020; pp. 2821-2826. [CrossRef]

118. He, D.; Zhang, S.; Chen, L.; Ying, E.; He, L.; Yang, N.; Zhang, R.; Xia, M.; Liu, H. Research on Temperature Calculation Method of Electrical Equipment Based on IR Data Compensation. In Proceedings of the 20195th International Conference on Environmental Science and Material Application, Guangzhou, China, 27-29 December 2019; Volume 440. [CrossRef]

119. OV9655 Color CMOS SXGA [Online Datasheet], OmniVision Technologies, Inc. Version 1.3. December 2005. Available online: www.arducam.com/downloads/modules/OV9655/ov9655_full.pdf (accessed on 15 September 2021).

120. OV7670/OV7171 COMS VGA $(640 \times 480)$ CameraChip Sensor with OmniPixel Technology [Online Datasheet], OmniVision Technologies, Inc. version 1.4. August 2006. Available online: web.mit.edu/6.111/www/f2016/tools/OV7670_2006.pdf (accessed on 15 September 2021).

121. OV2640 Colro CMOS UXGA (2,0 MegaPixel) CameraChip Sensor with OmniPixel Technology [Online Datasheet], OmniVision Technologies, Inc. version 1.6. February 2006. Available online: www.uctronics.com/download/cam_module/OV2640DS.pdf (accessed on 16 September 2021).

122. 1/2-Inch Megapixel CMOS Digital Image Sensor [Online Datasheet], Micron Technology, Inc. 2004. Available online: pdf1 .alldatasheet.com/datasheet-pdf/view/115168/MICRON/MT9M001.html (accessed on 16 September 2021).

123. Najib, S.M.; Idroas, M.; Ibrahim, M.N; Ab Wahab, N.; Rahim, N. New approach of optical tomography instrumentation system for particle sizing. In Proceedings of the Mechanical Engineering Research Day 2018 (Merd), Tunggal, Malacca, 29-31 May 2018; pp. 132-133. ISBN: 978-967-2145-20-2.

124. Infrared Array Sensor Grid-EYE (AMG88) [Online Datasheet], Pasasonic. Arpil 2017. Available online: cdn.sparkfun.com/assets/ 4/1/c/0/1/Grid-EYE_Datasheet.pdf (accessed on 16 September 2021).

125. MLX90640 $32 \times 24$ IR Array [Online Datasheet], Melexis Inspired Engineering, Version 12. December 2019. Available online: www.melexis.com/-/media/files/documents/datasheets/mlx90640-datasheet-melexis.pdf (accessed on 18 September 2021).

126. Carbon Monoxide Attacks Unexpectedly! Protect Your Family with a CO Alarm [Online], CO Alarms, VSE a.s, (Slovak Language). Available online: www.vse.sk/web/sk/domacnosti/produkty-a-sluzby/co-alarm (accessed on 18 September 2021).

127. Widodo, S.; Amin, M. Miftakhul and Supani, Ahyar and Handayani, Ade Silvia, Prototype Design of $\mathrm{CO}_{2}, \mathrm{CH}_{4}$ and SO 2 Toxic Gas Detectors in the Room Using Microcontroller-Based Fuzzy Logic, 3rd Forum in Research, Science, and Technology (First 2019) International Conference. J. Phys. Conf. Ser. 2020, 1500, 012107. [CrossRef]

128. Air Quality Gas Sensor (MQ135) [Datasheet Online], Zhengzhou Winsen Electronics Technology Co., Ltd. Version 1.4. March 2015. Available online: pdf1.alldatasheet.com/datasheet-pdf/view/1307647/WINSEN/MQ135.html (accessed on 18 September 2021).

129. Kelechi, A.H.; Alsharif, M.H.; Agbaetuo, C.; Ubadike, O.; Aligbe, A.; Uthansakul, P.; Kannadasan, R.; Aly, A.A. Design of a Low-Cost Air Quality Monitoring System Using Arduino and ThingSpeak. Comput. Mater. Contin. 2022, 70, 151-169. [CrossRef]

130. Ibrahim, A.A. Carbon Dioxide and Carbon Monoxide Level Detector. In Proceedings of the 2018 21st International Conference of Computer and Information Technology (ICCIT), Dhaka, Bangladesh, 21-23 December 2018; pp. 1-5. [CrossRef]

131. Bogdan, M. Home Alarm System with Arduino and LabVIEW. In Proceedings of the 15th International Conference on Virtual Learning (ICVL-2020), Bucharest, Romania, 31 October 31 2020; pp. 378-384.

132. Swain, K.B.; Santamanyu, G.; Senapati, A.R. Smart industry pollution monitoring and controlling using LabVIEW based IoT. In Proceedings of the 2017 Third International Conference on Sensing, Signal Processing and Security (ICSSS), Chennai, India, 4-5 May 2017; pp. 74-78. [CrossRef]

133. Solid Electrolyte $\mathrm{CO}_{2}$ Gas Sensor (MG811), Zhengzhou Winsen Electronics Technology Co., Ltd. Version 1.2. March 2015. Available online: datasheetspdf.com/pdf-file/1415579/Winsen/MG811/1 (accessed on 19 September 2021).

134. Maske, V.R.; Dhulap, V.P. Development of Handy Prototype Gas Sensors Kit for Monitoring of Ambient Green House Gases from Solid Waste Disposal Sites of Solapur City. In Proceedings of the Emerging Technologies: Micro to Nano (ETMN-2017), AIP Conference Proceedings 1989, Solapur, India, 23 July 2018. [CrossRef]

135. Mabunga, Z.; Magwili, G. Greenhouse Gas Emissions and Groundwater Leachate Leakage Monitoring of Sanitary Landfill. In Proceedings of the 2019 IEEE 11th International Conference on Humanoid, Nanotechnology, Information Technology, Communication and Control, Environment, and Management ( HNICEM), Laoag, Philippines, 29 November-1 December 2019; pp. 1-6. [CrossRef]

136. Géczy, A.; Kuglics, L.; Jakab, L.; Harsányi, G. Wearable Smart Prototype for Personal Air Quality Monitoring. In Proceedings of the 2020 IEEE 26th International Symposium for Design and Technology in Electronic Packaging (SIITME), Pitesti, Romania, 21-24 October 2020; pp. 84-88. [CrossRef]

137. Lasomsri, P.; Yanbuaban, P.; Kerdpoca, O.; Ouypornkochagorn, T. A Development of Low-Cost Devices for Monitoring Indoor Air Quality in a Large-Scale Hospital. In Proceedings of the 2018 15th International Conference on Electrical Engineering/Electronics, 
Computer, Telecommunications and Information Technology (ECTI-CON), Chiang Rai, Thailand, 18-21 July 2018 ; pp. $282-285$. [CrossRef]

138. CCS811Ultra-Low Power Digital Gas Sensor for Monitoring Indoor Air Quality [Datasheet, Online], Ams AG, Version 1.5. May 2018. Available online: pdf1.alldatasheet.com/datasheet-pdf/view/1047395/AMSCO/CCS811.html (accessed on 19 September 2021).

139. Wang, S.K.; Chew, S.P.; Jusoh, M.T.; Khairunissa, A.; Leong, K.Y.; Azid, A.A. WSN Based Indoor Air Quality Monitoring In Classrooms. In Proceedings of the 11th Asian Conference on Chemical Sensors (ACCS2015), AIP Conference Proceedings 1808, Penang, Malaysia, 16-18 November 2015. [CrossRef]

140. Zaharudin, S.Z.B.; Kazemi, M.; Malarvili, M.B. Designing a respiratory $\mathrm{CO}_{2}$ measurement device for home monitoring of asthma severity. In Proceedings of the 2014 IEEE Conference on Biomedical Engineering and Sciences (IECBES), Kuala Lumpur, Malaysia, 8-10 December 2014; pp. 230-234. [CrossRef]

141. Evita, M.; Zakiyyatuddin, A.; Seno, S.; Kumalasari, R.; Lukado, H.; Djamal, M. Development of a robust mobile robot for volcano monitoring application. J. Phys. Conf. Ser. 2020, 1572, 012016. [CrossRef]

142. Sarjerao, B.S.; Prakasarao, A. A Low Cost Smart Pollution Measurement System Using REST API and ESP32. In Proceedings of the 2018 3rd International Conference for Convergence in Technology (I2CT), Pune, India, 6-8 April 2018; pp. 1-5. [CrossRef]

143. Technical Data MQ-7 Gas Sensor [Datasheet, Online], Hanwei Electronics Co., Ltd. Available online: datasheetspdf.com/pdf-file/ 694312/Hanwei/MQ7/1 (accessed on 19 September 2021).

144. MQ-9 Semiconductor Sensor for CO/Combustible Gas, Hanwei Electronics Co., Ltd. Available online: www.haoyuelectronics com/Attachment/MQ-9/MQ9.pdf (accessed on 19 September 2021).

145. Rane, M.S.; Naik, A.R.; Vachhani, K. Real-time AQI Monitoring System: An Economical Approach Using Wireless Sensor Network. In Proceedings of the 2018 9th International Conference on Computing, Communication and Networking Technologies (ICCCNT), Bengaluru, India, 10-12 July 2018; pp. 1-6. [CrossRef]

146. Ng, K.M.; Suhaimi, M.A.H.M.; Ahmad, A.; Razak, N.A. Remote Air Quality Monitoring System by Using MyRIO-LabVIEW In Proceedings of the 2018 9th IEEE Control and System Graduate Research Colloquium (ICSGRC), Shah Alam, Malaysia, 3-4 August 2018; pp. 105-109. [CrossRef]

147. Firdaus, R.; Murti, M.A.; Alinursafa, I. Air Quality Monitoring System Based Internet of Things (IoT) Using LPWAN LoRa. In Proceedings of the 2019 IEEE International Conference on Internet of Things and Intelligence System (IoTaIS), Bali, Indonesia, 5-7 November 2019; pp. 195-200. [CrossRef]

148. Kodali, R.K.; Sarjerao, B.S. MQTT based air quality monitoring. In Proceedings of the 2017 IEEE Region 10 Humanitarian Technology Conference (R10-HTC), Dhaka, Bangladesh, 21-23 December 2017; pp. 742-745. [CrossRef]

149. Rojas-Ascate, C.S.; Escalaya-Angulo, A.; Tasayco-Abanto, J.; Huamaní-Navarrete, P.F. Implementation of a CO concentration measurement and alert prototype applying IoT and mobile application. In Proceedings of the 2019 IEEE 1st Sustainable Cities Latin America Conference (SCLA), Arequipa, Peru, 26-29 August 2019; pp. 1-6. [CrossRef]

150. Wonohardjo, E.P.; Kusuma, G.P. Air Pollution Mapping using Mobile Sensor Based on Internet of Things. Procedia Comput. Sci. 2019, 157, 638-645. [CrossRef]

151. Rathod, M.; Gite, R.; Pawar, A.; Singh, S.; Kelkar, P. An air pollutant vehicle tracker system using gas sensor and GPS. In Proceedings of the 2017 International Conference of Electronics, Communication and Aerospace Technology (ICECA), Coimbatore, India, 20-22 April 2017; pp. 494-498. [CrossRef]

152. Tao, M.M. Esign of Mine Safety Detection Alarm Based on Single-chip. In Proceedings of the 2014 International Conference on Automatic Control Theory and Application, Bangkok, Thailand, 17-19 June 2014; Atlantis Press: Paris, France, 2014 ; pp. 115-118. ISBN: 978-94-6252-011-0.

153. Kouda, S.; Bendib, T.; Barra, S.; Dendouga, A. ANN modeling of an industrial gas sensor behavior. In Proceedings of the 2018 International Conference on Communications and Electrical Engineering (ICCEE), El Oued, Algeria, 17-18 December 2018; pp. 1-4. [CrossRef]

154. McGranahan, D.A.; Poling, B.N. A Diy Thermocouple Datalogger is Suitably Comparable to a Commercial System for Wildland Fire Research. Fire Technol. 2021, 57, 1077-1093. [CrossRef]

155. McGranahan, D.A. FeatherFlame: An Arduino-Based Thermocouple Datalogging System to Record Wildland Fire Flame Temperatures in Agris. Angeland Ecol. Manag. 2021, 76, 43-47. [CrossRef]

156. Nasution, T.H.; Putramas, A.; Winto, S.; Fahmi; Siregar, I. Automatic Coffee Roaster Design Using Arduino. In Proceedings of the 6th International Conference on Manufacturing, Optimization, Industrial and Material Engineering: MOIME18, AIP Conference Proceedings 2018, Bandung, Indonesia, 25 March 2018; Volume 2044. [CrossRef]

157. Abidin, A.S.Z.; Kifli, M.Z.; Jamali, A.; Muslimen, R. Development of Black Pepper Rotary Drum Dryer System. Int. J. Integr. Eng. 2021, 12, 11-19. [CrossRef]

158. Thedsakhulwong, A.; Hernmek, P. Development of the low-cost hot plate temperature controller using Arduino Uno R3. J. Phys. Conf. Ser. 2018, 1144, 012169. [CrossRef]

159. Gosai, M.; Bhavsar, S.N. Experimental Study on Temperature Measurement in Turning Operation of Hardened Steel (EN36). In Proceedings of the 3rd International Conference on Innovations in Automation and Mechatronics Engineering 2016, ICIAME 2016, Vallabh Vidhyanagar, India, 5-6 February 2016; Volume 23, pp. 311-318. [CrossRef] 
160. Abdullah, M.H.; Ghani, S.C.; Zaulkafilai, Z.; Tajuddin, S.N. Development open source microcontroller based temperature data logger. In Proceedings of the 4th International Conference on Mechanical Engineering Research (ICMER2017), Pahang, Malaysia, 1-2 August 2017; Volume 257. [CrossRef]

161. Nabila, K.T.; Akter, T.; Hossain, M.; Rahman, M.H.; Alam, R. Multi-probe Thermocouple Transducer For Simultaneous Temperature Measurement. In Proceedings of the 2019 IEEE 5th International Conference for Convergence in Technology (I2CT), Bombay, India, 29-31 March 2019; pp. 1-4. [CrossRef]

162. Karan, Y.; Kahveci, S. Wireless measurement of thermocouple with microcontroller. In Proceedings of the $201523 \mathrm{nd}$ Signal Processing and Communications Applications Conference (SIU), Malatya, Turkey, 16-19 May 2015; pp. 120-123. [CrossRef]

163. Yordanov, K.; Zlateva, P.; Hadzhidimov, I.; Stoyanova, A. Testing and clearing the high temperature module error from 0 to $1250{ }^{\circ} \mathrm{C}$ for measurement with $16 \mathrm{~K}$-type thermocouples. In Proceedings of the 2018 20th International Symposium on Electrical Apparatus and Technologies (SIELA), Bourgas, Bulgaria, 3-6 June 2018; pp. 1-4. [CrossRef]

164. Ostromecky, M. Thermocouples: Function, Types, Selection and Application [Online], enDAQ. Available online: blog.endaq.com/ thermocouples-function-types-selection-and-application (accessed on 19 September 2021).

165. Types of Thermocouple [Online], REOTEMP Instrument Corporation. Available online: www.thermocoupleinfo.com/ thermocouple-types.htm (accessed on 19 September 2021).

166. Eitel, J.U.H.; Hö, B.; Vierling, L.A.; Abellán, A.; Asner, G.P.; Deems, J.S.; Glennie, C.L.; Joerg, P.C.; Lewinter, A.L.; Magney, T.S.; et al. Beyond 3-D: The new spectrum of lidar applications for earth and ecological sciences. Remote Sens. Environ. 2016, 186, 372-392. [CrossRef]

167. Ebrahim, M.A.-B. 3D Laser Scanners' Techniques Overview. Int. J. Sci. Res. 2015, 4, 5-611.

168. Toth, C.; Jóźków, G. Remote sensing platforms and sensors: A survey. ISPRS J. Photogramm. Remote Sens. 2016, 115, 22-36. [CrossRef]

169. Colomina, I.; Molina, P. Unmanned aerial systems for photogrammetry and remote sensing: A review. ISPRS J. Photogramm. Remote Sens. 2014, 92, 79-97. [CrossRef]

170. Nuchter, A. 3D Robotic Mapping. In Springer Tracts in Advanced Robotics; Springer: Berlin/Heidelberg, Germany, 2009; Volume 52, ISBN 978-3-540-89883-2.

171. Yilmaz, V. Automated ground filtering of LiDAR and UAS point clouds with metaheuristics. Opt. Laser Technol. 2021, 138, 106890. [CrossRef]

172. Baras, N.; Nantzios, G.; Ziouzios, D.; Dasygenis, M. Autonomous Obstacle Avoidance Vehicle Using LIDAR and an Embedded System. In Proceedings of the 2019 8th International Conference on Modern Circuits and Systems Technologies (MOCAST), Thessaloniki, Greece, 13-15 May 2019; pp. 1-4. [CrossRef]

173. Fouad, A.M.; Sharkawy, R.M.; Onsy, A. Fixed Obstacle Detection for Autonomous Vehicle. In Proceedings of the 2019 IEEE Conference on Power Electronics and Renewable Energy (CPERE), Aswan, Egypt, 23-25 October 2019; pp. 217-221. [CrossRef]

174. Singh, A.K.; Negi, A.; Azad, S.; Mudali, S. Fuzzy Based Controller for Lidar Sensor of an Autonomous Vehicle. Energy Procedia 2017, 117, 1160-1164. [CrossRef]

175. Wang, Y.; Goila, A.; Shetty, R.; Heydari, M.; Desai, A.; Yang, H. Obstacle Avoidance Strategy and Implementation for Unmanned Ground Vehicle Using LIDAR. SAE Int. J. Commer. Veh. 2017, 10, 50-55. [CrossRef]

176. Singh, S.A.A.K.; Negi, A.; Mudali, S. Analysis of automatic sensing model of an autonomous vehicle. In Proceedings of the 2017 International Conference on Inventive Systems and Control (ICISC), Coimbatore, India, 19-20 January 2017; pp. 1-5. [CrossRef]

177. Denysyuk, P.; Teslyuk, V.; Chorna, I. Development of mobile robot using LIDAR technology based on Arduino controller. In Proceedings of the 2018 XIV-th International Conference on Perspective Technologies and Methods in MEMS Design (MEMSTECH), Lviv, Ukraine, 18-22 April 2018; pp. 240-244. [CrossRef]

178. Vlaminck, M.; Philips, W.; Luong, H.Q. Liborg: A lidar-based Robot for Efficient 3D Mapping. In Applications of Digital Image Processing Xl; 19 September 2017; Volume 10396. Available online: https://biblio.ugent.be/publication/8530329/file/8544719.pdf (accessed on 24 January 2022).

179. Gatesichapakorn, S.; Takamatsu, J.; Ruchanurucks, M. ROS based Autonomous Mobile Robot Navigation using 2D LiDAR and RGB-D Camera. In Proceedings of the 2019 First International Symposium on Instrumentation, Control, Artificial Intelligence, and Robotics (ICA-SYMP), Bangkok, Thailand, 16-18 January 2019; pp. 151-154. [CrossRef]

180. Hutabarat, D.; Rivai, M.; Purwanto, D.; Hutomo, H. Lidar-based Obstacle Avoidance for the Autonomous Mobile Robot. In Proceedings of the 2019 12th International Conference on Information \& Communication Technology and System (ICTS), Surabaya, Indonesia, 18 July 2019; pp. 197-202. [CrossRef]

181. Hossain, S.; Doukhi, O.; Jo, Y.; Lee, D.-J. Deep Reinforcement Learning-based ROS-Controlled RC Car for Autonomous Path Exploration in the Unknown Environment. In Proceedings of the 2020 20th International Conference on Control, Automation and Systems (ICCAS), Busan, Korea, 13-16 October 2020; pp. 1231-1236. [CrossRef]

182. Ponte, S.; Ariante, G.; Papa, U.; Del Del Core, G. An Embedded Platform for Positioning and Obstacle Detection for Small Unmanned Aerial Vehicles. Electronics 2020, 9, 1175. [CrossRef]

183. Torres, F.M.; Tommaselli, G.; Maria, A. A Lightweight Uav-Based Laser Scanning System for Forest Application. Bol. Cienc. Geod. 2018, 24, 318-334. [CrossRef]

184. Kadirova, S.Y.; Nenov, T.R. Design of Power Wheelchair Controller. In Proceedings of the 2020 7th International Conference on Energy Efficiency and Agricultural Engineering (EE\&AE), Ruse, Bulgaria, 12-14 November 2020; pp. 1-4. [CrossRef] 
185. Ponce, R.; Canchingre, G.M.; Velarde, P.; Moya, M. Design and Construction of an Automatic Transport System Inside the Home for People with Reduced Mobility. In Proceedings of the 2018 International Conference on Information Systems and Computer Science (INCISCOS), Quito, Ecuador, 13-15 November 2018; pp. 88-93. [CrossRef]

186. Pathak, P. Smart Helmet with Motorbike unit for Accident and Rash Driving Detection. In Proceedings of the 2020 IEEE International Conference on Advances and Developments in Electrical and Electronics Engineering (ICADEE), Coimbatore, India, 10-11 December 2020; pp. 1-6. [CrossRef]

187. Van Brummelen, J.; Emran, B.; Yesilcimen, K.; Najjaran, H. Reliable and Low-cost Cyclist Collision Warning System for Safer Commute on Urban Roads. In Proceedings of the Reliable and Low-cost Cyclist Collision Warning System for Safer Commute on Urban Roads 2016, Budapest, Hungary, 9-12 October 2016; pp. 3731-3735. [CrossRef]

188. Verdict Media Strategies, iRobot 510 PackBot Multi-Mission Robot [Online], Army Technology. August 2021. Available online: https:/ / www.army-technology.com/projects/irobot-510-packbot-multi-mission-robot/ (accessed on 22 January 2022).

189. Ismail, R.; Muthukumaraswamy, S. Military Reconnaissance and Rescue Robot with Real-Time Object Detection. In Intelligent Manufacturing and Energy Sustainability; Reddy, A., Marla, D., Favorskaya, M.N., Satapathy, S.C., Eds.; Smart Innovation, Systems and Technologies; Springer: Singapore, 2021; Volume 213. [CrossRef]

190. Howe \& Howe, Thermite, First Commercial Firefighting Robot Sold in the U.S. [Online]. Available online: https://www. howeandhowe.com/civil/thermite (accessed on 22 January 2022).

191. Shark Robotics, Colossus [Online]. The Official Web Page of Shrk Robotics Company. Available online: https://www.sharkrobotics.com/colossus (accessed on 22 January 2022).

192. ReconRobotics, Recon Scout [Online], The Official Web Page of ReconRobotics Company. Available online: https://reconrobotics $\mathrm{com} /$ (accessed on 22 January 2022).

193. Israel Defense, ODF Optronics [Online], The Official Web Page of Israel Defense [Used January 2022]. Available online: https:/ / www.israeldefense.co.il/en/ (accessed on 22 January 2022).

194. Szynkarczyk, P.; Czupryniak, R.; Trojnacki, M.; Andrzejuk, A. Current state and development tendency inmobile robots for special applications. In Proceedings of the International Conference WEISIC 6th Workshopon European Scientific and Industrial Collaboration on Promoting Advanced Technologies in Manufacturing, Bucharest, Romania, 25-26 September 2008; Volume 8, pp. 30-41.

195. Enforcement Technology Grupe, Eyeball r1 Surveillance Sensor Systems [Online], The Future of Technology... Today! Available online: https:/ / etgi.us/ (accessed on 22 January 2022). 